Article

\title{
Numerical Simulation of Water Transport in a Proton Exchange Membrane Fuel Cell Flow Channel
}

\author{
Jun Shen, Zhichun Liu *(D), Fan Liu and Wei Liu * \\ School of Energy and Power Engineering, Huazhong University of Science and Technology, Wuhan 430074, \\ China; shenjun@hust.edu.cn (J.S.);13723408526@163.com (F.L.) \\ * Correspondence: zcliu@hust.edu.cn (Z.L.);w_liu@hust.edu.cn (W.L.)
}

Received: 6 June 2018; Accepted: 2 July 2018; Published: 5 July 2018

\begin{abstract}
Water management of proton exchange membrane fuel cells (PEMFCs) is crucial to maintain high performance and stable operation. The flow channel is an indispensable part of PEMFCs, which allows the reactant gases to flow into the system, and the liquid water to be removed from the fuel cells. A transient 3D model based on volume of fluid methodology is used to study the dynamic characteristics of gas-liquid two-phase flow in a PEMFC flow channel. The structure of the flow channel, the wettability of channel surfaces, the air inlet velocity, the dimensions of the water droplets, and the effect of phase transition are considered to obtain the optimal solution. The results show that the water droplet transport process is seriously affected by the wettability of the channel surfaces. A modified surface design with varied static surface contact angle could perform the detachment without external force with an appropriate initial velocity. Besides, phase transitions could seriously influence the form and the distribution of water existing in the channel.
\end{abstract}

Keywords: two-phase; volume of fluid (VOF); water transport; fuel cell; phase transition

\section{Introduction}

PEMFCs represent one of the most promising clean energy technologies [1-4]. Good water management is important to maintain high performance and stable operation for fuel cell commercial use. Humidified and reaction product water [5] could easily become supersaturated inside the fuel cell due to consumption of reactant gases, and excess water would cause flooding inside the fuel cell, which leads to not only performance losses and component damage [6,7], but also the safety issue of cell reversal. Investigations of water transport in PEMFC are important to guide the design of fuel cells.

So far, a number of studies [8-15] have discussed the fuel cell water transport issue by numerical simulation and experimental research. Lottin et al. [11] used a pseudo-2D model of a PEMFC including mass transport limitations during the process of electrode flooding, and the limiting current defined by the appearance of liquid in the cell could be determined. A condenser was introduced to recover water in the exhaust gas by Wan et al. [12,13], and their experimental results showed that water recycling could easily realize the air self-humidifying by a proper condensation temperature. Liu et al. [14] investigated the influence of phase transition on heat balance in a PEMFC stack, which was theoretically and experimentally proved to be negligible. Djilali and Lu [15] presented an analysis of transport phenomena in a PEMFC focusing on the effects of temperature and pressure. It was found that water transport was greatly affected by non-uniform effects.

The above references study the water transport of the whole fuel cell, with the limitations of mass transport, temperature distribution and so on. Water droplet dynamics in PEMFC flow channels, in the term of two-phase flow, as the most intuitive formulation of water transport from the inside to the outside, is receiving increased attention. Anderson et al. [16] summarized gas-liquid two-phase flow in gas channels of PEMFCs. Experimental approaches and computational fluid dynamics (CFD) 
simulations to solve water flooding issue were presented in details in the paper. Zhu et al. [17] studied the mechanism of a water droplet emerging from a hole in the gas diffusion layer surface using a transient 3D two-phase model by means of the volume of fluid (VOF) methodology. The main conclusion was that the emerging water droplet behavior depended on the wettability of the gas diffusion layer (GDL) surface. Jiao et al. [18] proposed three types of innovative GDLs to solve the liquid water flooding problem using transient 3D two-phase model in FLUENT. The results showed that the liquid water flow patterns would be greatly affected by the GDLs' design. Amara et al. [19] studied the droplet behavior in a PEMFC flow channel using a Lattice Boltzmann simulation based on the Shan-Chen scheme. The droplet behavior was presented under different capillary number $\mathrm{Ca}$ and the wettability conditions. Banerjee et al. [20] focused on quantifying the liquid water and identifying the flow patterns in the channels using MATLAB. The results showed the dominant flow patterns and liquid water was quantified in the flow channels for conditions of different temperature, inlet RH and current density. Gao et al. [21,22] studied the impact process and the coalescence process of nanodroplets using a molecular dynamics (MD) simulation, which would be helpful to gain insight into the mechanism of the dynamical behavior of the nanodroplets.

Aside from the studies mentioned above, there are also lots of visualization experiments of water transport in a PEMFC. Ous et al. [23] used a transparent PEMFC to visualize the water droplet formation process. The results showed that the water accumulation occurred first in the central section of the serpentine channel, while no droplets were found in the bends, and flooding was susceptible to the airflow. Lee et al. [24] conducted a visualization experiment to investigate the flow phenomena in the channels and the PEMFC stack. The results clearly revealed that anode flooding was more severe than cathode flooding, and voltage fluctuations were strongly related to flooding in the PEMFC stack. Focusing on observation of liquid water flow state in the turns of gas channels of PEMFCs, Zhan et al. [25] studied water behavior under different operating conditions with a high-speed camera. Using a combined theoretical and experimental study, Kumbur et al. [26] paid close attention to the influence of controllable engineering parameters on liquid droplet deformation. The results showed that droplet dimension, channel size and wettability all influenced the instability of the droplets.

In this paper, a transient 3D model of three different configurations based on the VOF methodology is developed to study the dynamic characteristics of gas-liquid two-phase flow in the flow channels of a PEMFC. The configuration of a straight channel with a water droplet initialized at the inlet is used for a basic study applied to hydrogen/air fuel cell. The proposed modified surface design with varied static surface contact angle is a novel hydrogen/oxygen fuel cell design for spontaneous detachment of water droplets. The configuration of a straight channel with a water inlet hole in the GDL is closer to practice, and the phase transitions during water transport have also been considered by adding user-defined functions (UDFs). Although the configurations ignore the mechanism of water production, the study results should is beneficial for fuel cell design.

\section{Numerical Methodology}

\subsection{Mathematical Models}

The volume of fluid (VOF) model is a multi-phase model which uses an advanced Lagrangian interface tracking scheme for simulating the motion of gas-liquid interfaces in micro-channels.

\subsubsection{Configuration 1: Conventional Straight Channel}

The physical dimensions of the micro-channel shown in Figure 1 are $1 \mathrm{~mm}$ (width) $\times 1 \mathrm{~mm}$ (height) $\times 5 \mathrm{~mm}$ (length), with hexahedral mesh grids. The number of grids is 320,000 . The water droplet is set at the center of the gas channel $0.25 \mathrm{~mm}$ from the inlet, and the droplets initialized at other positions could be predicted based on the center position condition. In addition to variables such as air inlet velocity, static contact angles of GDL surface (the bottom surface) and side walls, the supplementary settings are listed below: 
(a) The operating pressure is set to $1 \mathrm{~atm}$.

(b) The gas-liquid surface tension coefficient is set to $0.072 \mathrm{~N} \cdot \mathrm{m}^{-1}$.

(c) The time step size is set to $10^{-6} \mathrm{~s}$.

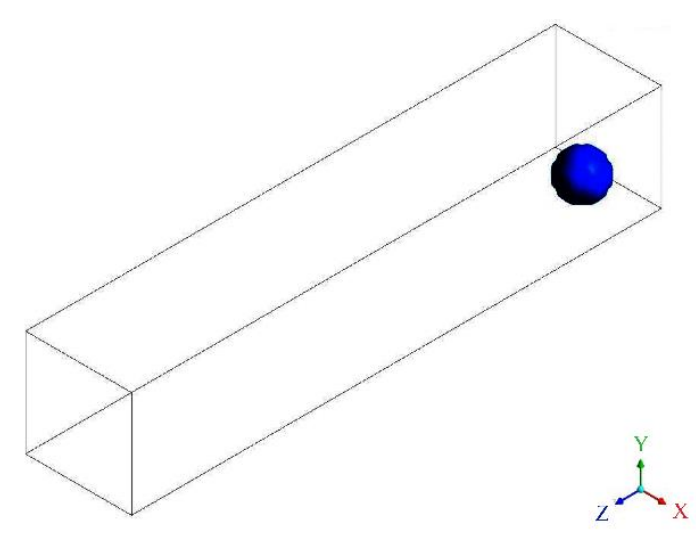

Figure 1. A straight channel with a water droplet initialized at the inlet.

\subsubsection{Configuration 2: Modified GDL Surface}

In a hydrogen/oxygen dead-end system, the gas flow is too weak to overcome the wall adhesion force. To accelerate the spontaneous detachment of droplets, the GDL surface has been modified as shown in Figure 2. There are many studies discussing the water transport issue in the gas diffusion layer of PEMFCs [27-30], and the contact angle of the GDL varies with the structure characteristics of the GDL, with contact angles ranging from $110^{\circ}$ to $156^{\circ}$, so the GDL surface is divided into five parts, and for our numerical simulation the static surface contact angles are set to $145^{\circ}, 135^{\circ}, 125^{\circ}, 115^{\circ}$ and $105^{\circ}$ from the inlet to the outlet, respectively. Moreover, except for the time step size which is set to $1 \times 10^{-5} \mathrm{~s}$, the other supplementary settings are the same as in configuration 1 .

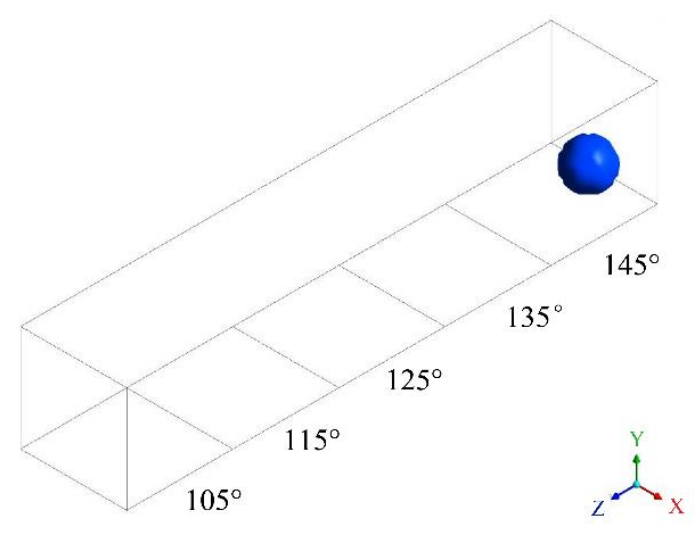

Figure 2. Modified GDL surface with varied static surface contact angle.

\subsubsection{Configuration 3: Straight Channel with a Water Inlet Hole}

Due to the porous structure of the gas diffusion layer in PEMFCs, liquid water emerges from the hole in the GDL surface, then accumulates in the gas channel until it is blown away by the reactant flow. Adding a water inlet hole is closer to the actual operation conditions of fuel cells. Moreover, phase transition during the operating process will be considered in the simulation. The air inlet velocity is set to $5 \mathrm{~m} \cdot \mathrm{s}^{-1}$, while the water inlet velocity is $0.5 \mathrm{~m} \cdot \mathrm{s}^{-1}$. The time step is $10^{-5} \mathrm{~s}$ without considering phase transitions, and when considering phase transitions, the time step size is $10^{-6} \mathrm{~s}$. Figure 3 presents the schematic illustration of the configuration. 


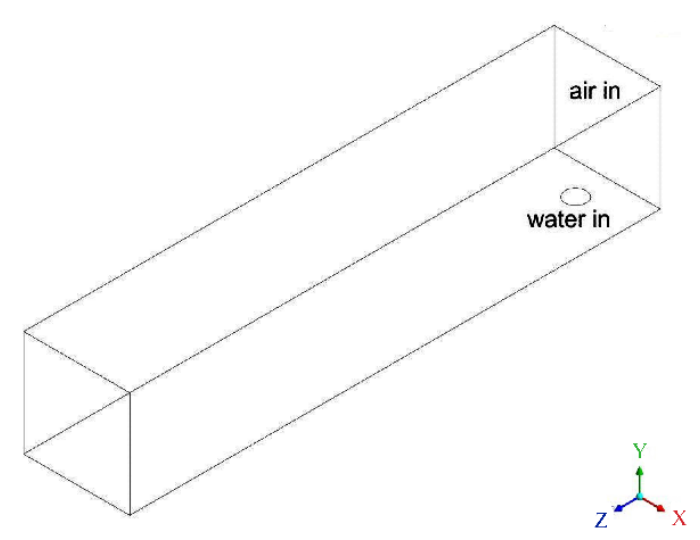

Figure 3. A straight channel with a water inlet hole.

\subsection{Governing Equation}

2.2.1. Without Considering Phase Transition

$$
\frac{\rho}{\partial t}+\nabla(\rho \cdot \vec{u})=0
$$

where $\rho$ is the volume averaged density.

Volume conservation equation

$$
\frac{\partial \alpha_{i}}{\partial t}+\vec{u} \cdot \nabla \alpha_{i}=0
$$

$\alpha_{i}$ is the volume fraction of species $i, \alpha_{1}$ represents the gas phase, and $\alpha_{2}$ represents the liquid phase. Momentum conservation equation

$$
\begin{aligned}
\frac{\partial(\rho \vec{u})}{\partial t}+\nabla \cdot(\rho \vec{u} \vec{u}) & =-\nabla p+\nabla \cdot\left[\mu\left(\nabla \vec{u}+\nabla \vec{u}^{t}\right)\right] \\
& +\rho \vec{g}+\vec{F}
\end{aligned}
$$

where,

Phase volume: $\alpha_{1}+\alpha_{2}=1$

Volume averaged density: $\rho=\alpha_{2} \rho_{2}+\left(1-\alpha_{2}\right) \rho_{1}$

Volume averaged dynamic viscosity: $\mu=\alpha_{2} \mu_{2}+\left(1-\alpha_{2}\right) \mu_{1}$

Source term of momentum conservation equation due to surface tension and wall adhesion:

$$
\vec{F}=2 \sigma_{i j} \rho k_{i} \nabla \alpha_{i} /\left(\rho_{i}+\rho_{j}\right)
$$

$\sigma_{i j}$ is surface tension, and $k$ is the radius of curvature.

\subsubsection{Considering Phase Transition}

Mass conservation equation

$$
\frac{\partial \rho_{i}}{\partial t}+\nabla\left(\rho_{i} \cdot \vec{u}\right)=S_{m}
$$

$S_{m}$ is the source term of mass conservation equation. For liquid water, $S_{m}$ is the amount of water condensed during the transport process. For water vapor, $S_{m}$ is equal to the amount of condensed water and opposite in sign.

Volume conservation equation

$$
\frac{\partial\left(\rho_{i} \alpha_{i}\right)}{\partial t}+\nabla\left(\rho_{i} \alpha_{i} \cdot \vec{u}\right)=r_{w}
$$


where species $i$ represents the species of liquid water, $r_{w}$ is the condensation rate [31].

$$
r_{w}=c_{r} \max \left(\left[\left(1-\partial_{l}\right) \frac{P_{w v}-P_{s a t}}{R T} M_{w, H_{2} \mathrm{O}}\right],\left[-\partial_{l} \rho_{l}\right]\right)
$$

where $-r_{w}$ is evaporation rate, $c_{r}$ is the condensation rate constant, and the value is set to $100 \mathrm{~s}^{-1}$.

Energy conservation equation

$$
\frac{\partial\left(\rho c_{p} T\right)}{\partial t}+\nabla\left(\rho c_{p} \vec{u} T\right)=\nabla \cdot\left(k^{e f f} \nabla T\right)+S_{Q}
$$

where $c_{p}$ is the mixture-averaged specific capacity, $k^{e f f}$ is the thermal conductivity. $S_{Q}$ is the source term of energy conservation equation, which is the heat exchange quantity due to phase transition.

$$
S_{Q}=h_{L} r_{w}
$$

$h_{L}$ is the latent heat of vaporization.

The momentum conservation equation is the same as in the model without considering phase transition.

\section{Results and Discussion}

\subsection{Configuration of the Straight Channel}

Figure 4 showed cases of hydrophilic GDL surfaces and sidewalls with static contact angles of $45^{\circ}$ at different air inlet velocities. Deformation of water droplets occurred, where the bottom part of the droplets spread on the GDL surface and the top part kept a spherical shape during the first period of time. Then the whole droplet spread downstream and formed a water film covering the GDL surface as time evolved. At $1 \mathrm{~ms}$, the water films were in the latter part of the flow channel contacting with the side walls at the air inlet velocity of $4 \mathrm{~m} \cdot \mathrm{s}^{-1}$ and $5 \mathrm{~m} \cdot \mathrm{s}^{-1}$, and when the inlet velocity was $6 \mathrm{~m} \cdot \mathrm{s}^{-1}$, the film flowed out of the channel. Obviously, the droplet was closer to the outlet with higher air inlet velocities, meanwhile more parasitic power was consumed.

Two representative contact angles, $45^{\circ}$ and $135^{\circ}$, was chosen to study the influence of wettability on the droplet dynamics in the flow channel with the same flow inlet velocity of $5 \mathrm{~m} \cdot \mathrm{s}^{-1}$. Figure 5 shows the time evolution of the droplet in $1 \mathrm{~ms}$ with the interval of $0.2 \mathrm{~ms}$, respectively. The water droplet deformed, spread, and moved in the form of a water film when the contact angle was $45^{\circ}$. With the spreading of the water film, the liquid water extended to the side walls and was adsorbed at $0.8 \mathrm{~ms}$. When the contact angle was $135^{\circ}$, the initial regular spherical droplet deformed, rolled in the flow channel, maintaining the basic spherical shape. At the time of $1 \mathrm{~ms}$, the water droplet had already reached the outlet of the flow channel for hydrophobic surfaces, though the water film was also close to the outlet for the hydrophilic surface. Besides, the water film covering the bottom of flow channel would definitely hinder the mass transfer of reactants and result in performance degradation of the fuel cell. The results suggested that a hydrophobic surface would be considered to be a preferable design for water drainage. 


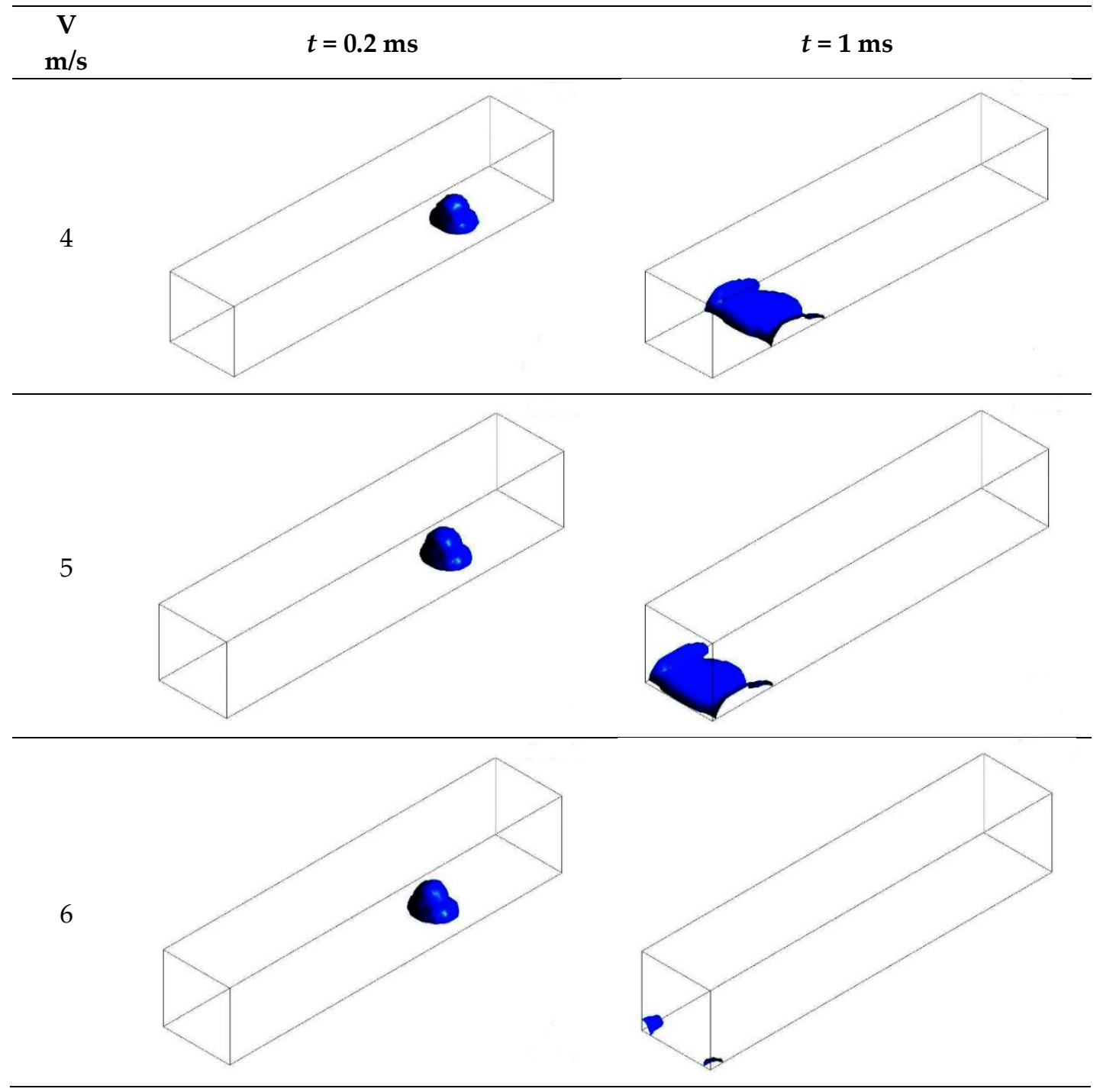

Figure 4. Water droplet behaviors at different inlet velocity (the GDL surface contact angle is $45^{\circ}$ and the side walls contact angles are $45^{\circ}$ ).

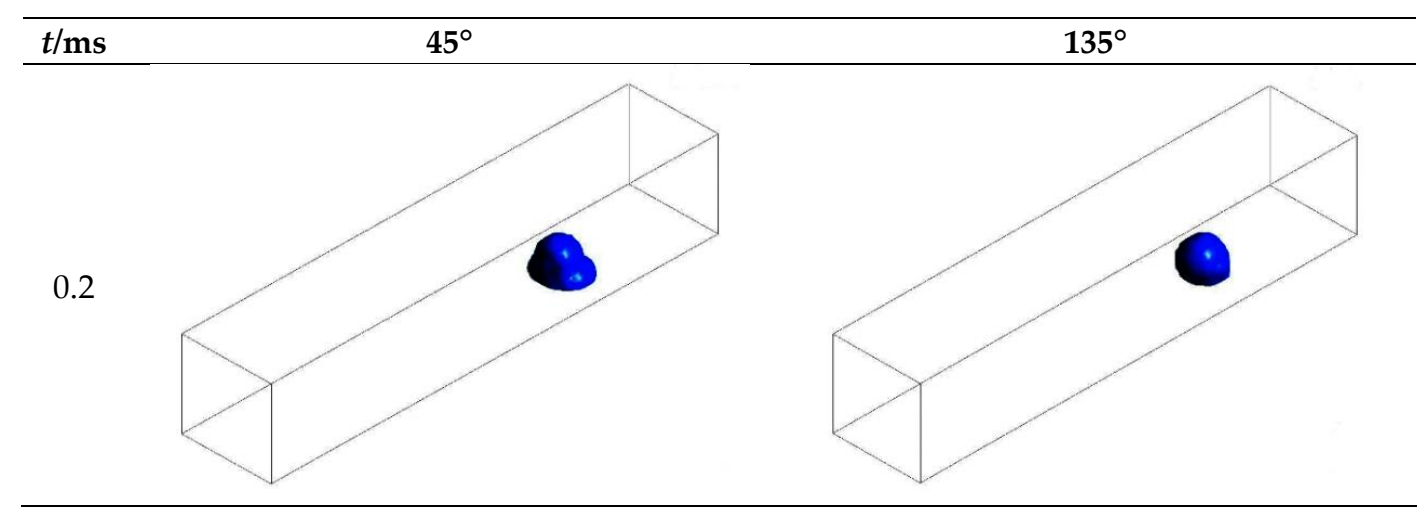

Figure 5. Cont. 

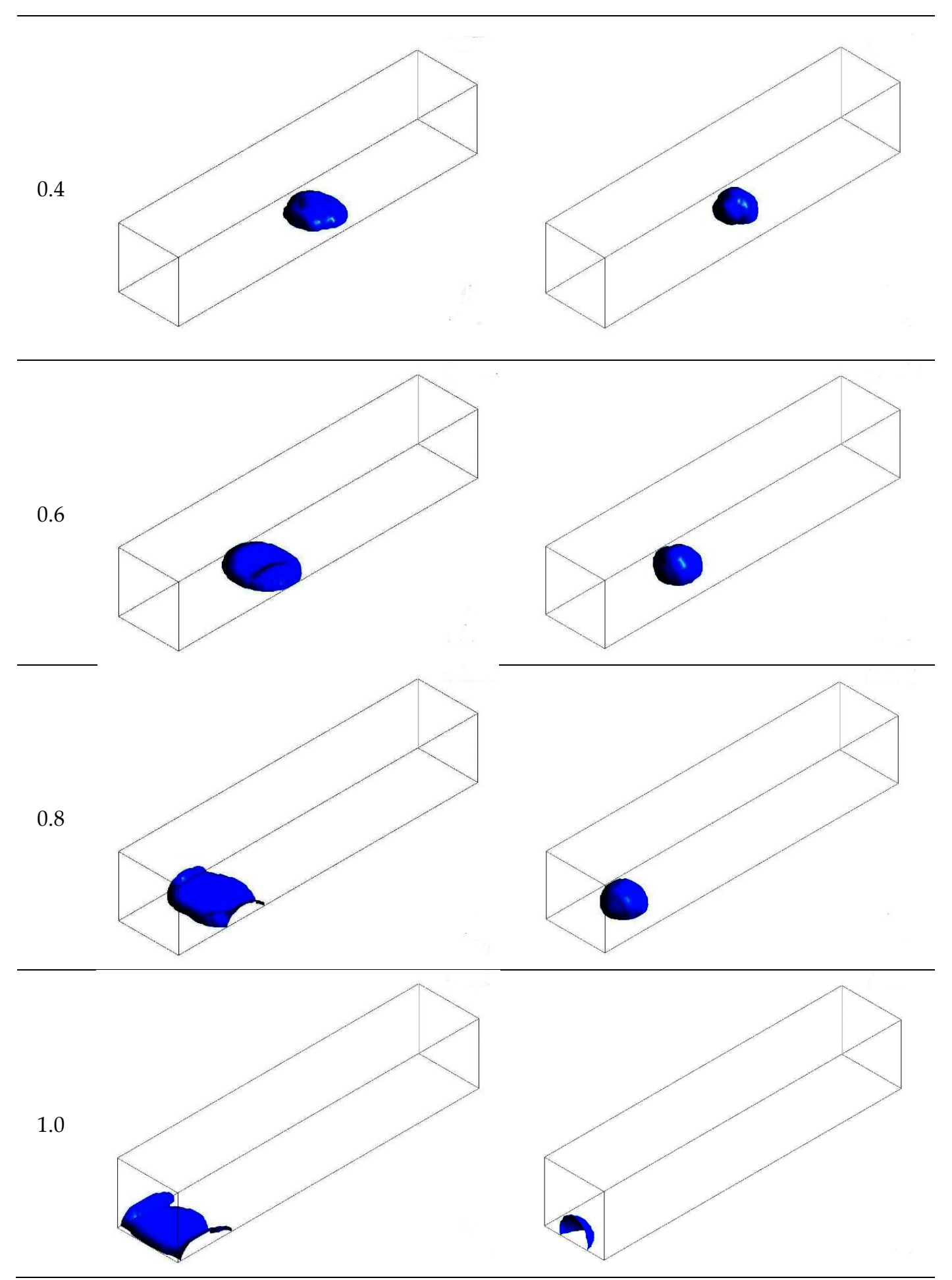

Figure 5. Time evolution of the water droplet (all the surface contact angles are $45^{\circ}$ and all the surfaces contact angles are $135^{\circ}$ ).

The behavior of water droplets of different initial radius with the same air inlet velocity of $5 \mathrm{~m} \cdot \mathrm{s}^{-1}$ was also studied in the paper, and the selection criteria of radius referred to [32,33]. At the time of $1 \mathrm{~ms}$, as seen from Figures 6 and 7, the water droplets of $0.2 \mathrm{~mm}$ radius moved out of flow channel first, while the water droplets of $0.1 \mathrm{~mm}$ just stayed in the flow channel, regardless of the boundary wettability. 


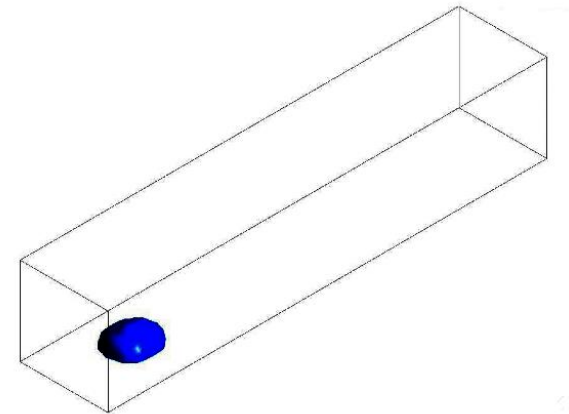

(a) $r=0.1 \mathrm{~mm}$

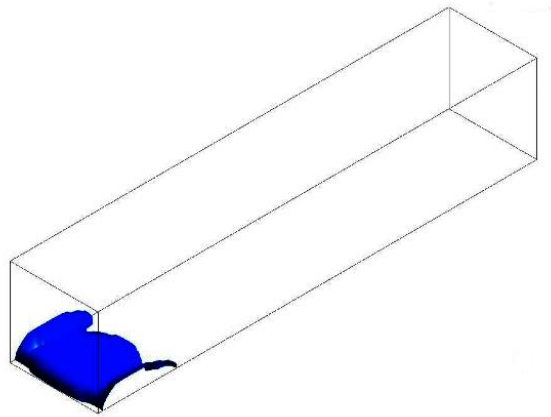

(b) $r=0.15 \mathrm{~mm}$

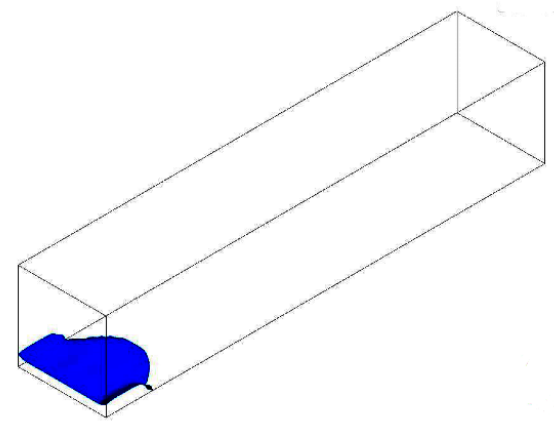

(c) $r=0.2 \mathrm{~mm}$

Figure 6. Water droplet behavior at different initial radius $(t=1 \mathrm{~ms}$ and all the surface contact angles are $\left.45^{\circ}\right)$.

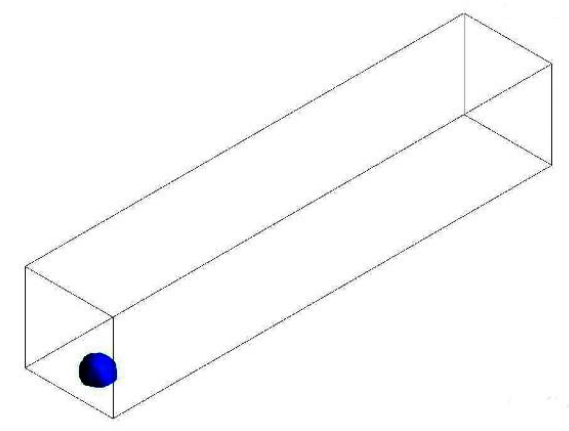

(a) $r=0.1 \mathrm{~mm}$

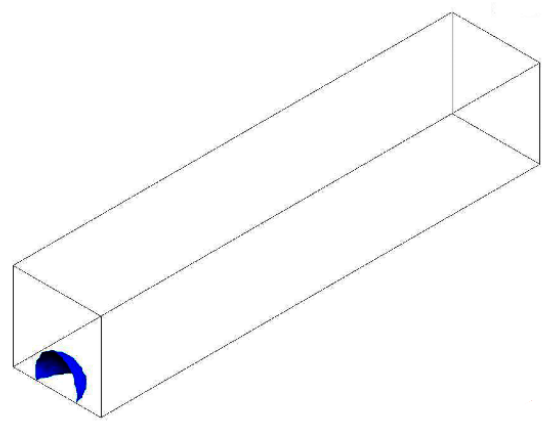

(b) $r=0.15 \mathrm{~mm}$

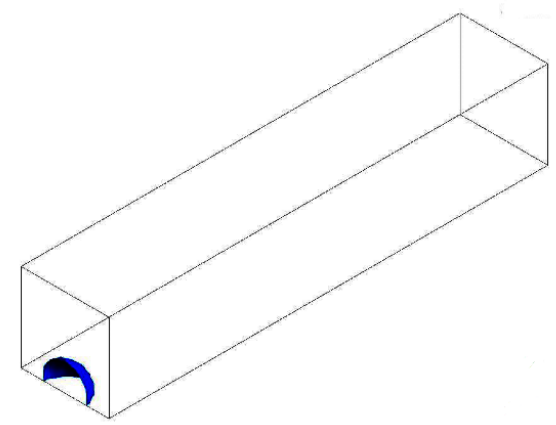

(c) $r=0.2 \mathrm{~mm}$

Figure 7. Water droplet behavior at different initial radius $(t=1 \mathrm{~ms} \&$ all the surfaces contact angles are $135^{\circ}$ ). 
According to the force analysis of water droplets, for smaller droplets, the drag force was smaller with smaller windward area, and the surface tension and wall adhesion were larger with larger curvature, as calculated by Equation (4). Therefore the movement of the water droplet with radius of $0.1 \mathrm{~mm}$ was slower than that of droplets with a radius of $0.15 \mathrm{~mm}$ and $0.2 \mathrm{~mm}$.

\subsection{Configuration of Modified GDL Surface}

From the inlet to the outlet, gradually increasing and decreasing static surface contact angles are the two basic ways to modify the GDL surface. The GDL surface was divided into five parts, and the static surface contact angles were $105^{\circ}, 115^{\circ}, 125^{\circ}, 135^{\circ}$ and $145^{\circ}$ from the inlet to outlet or from the outlet to inlet, respectively.

Figure 8 shows the motion characteristics of the droplet in the channel with varied wettability at different moments. At the time of $2 \mathrm{~ms}$, the water droplet passed the first interface of wettability discontinuity in both the two form flow channels, and the moving distance along the decreasing contact angle flow channel was slightly greater than that along an increasing contact angle flow channel. In addition, the droplet was almost a standard sphere in a decreasing contact angle flow channel, while part of the droplet infiltrated the bottom of increasing contact angle flow channels. Then the water droplet had arrived the third region with decreasing contact angle, while the droplet stayed in the second region with increasing contact angle at $4 \mathrm{~ms}$. This was due to the larger contact angle of the inlet part where a smaller contact area led to a smaller wall adhesion, so the droplet in a decreasing flow channel moved farther with the same initial kinetic energy. As well, the water droplet reached the outlet in the decreasing flow channel at $10 \mathrm{~ms}$, almost $2 \mathrm{~mm}$ distance ahead of the water droplet in an increasing flow channel. Because the initial movement resistance was large, the moving distance was short in the initial stage in the increasing flow channel, and the advancement of the optimization structure could not be realized.
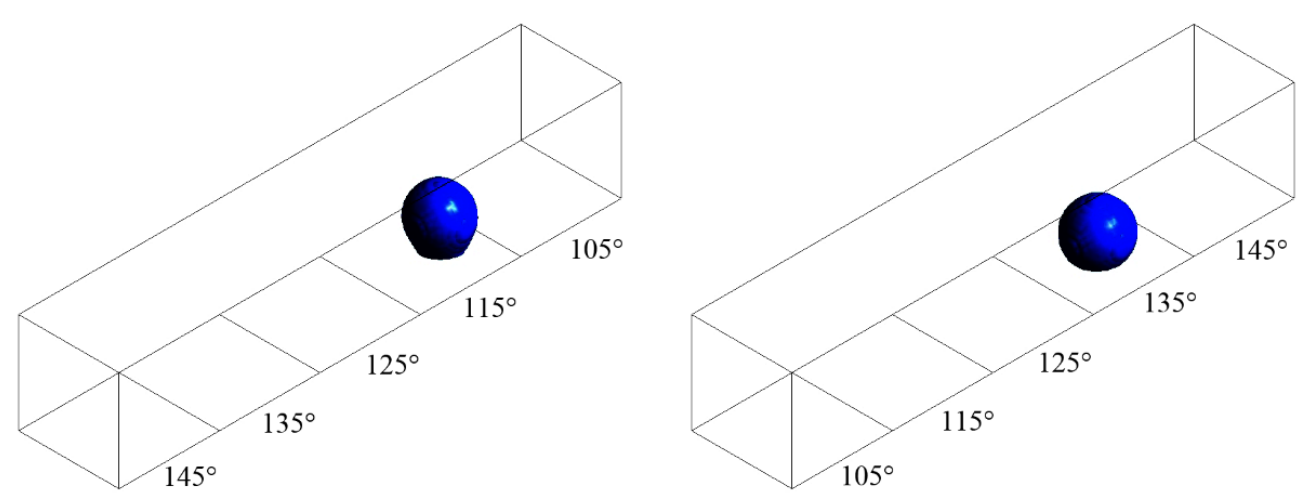

(a) $t=2 \mathrm{~ms}$
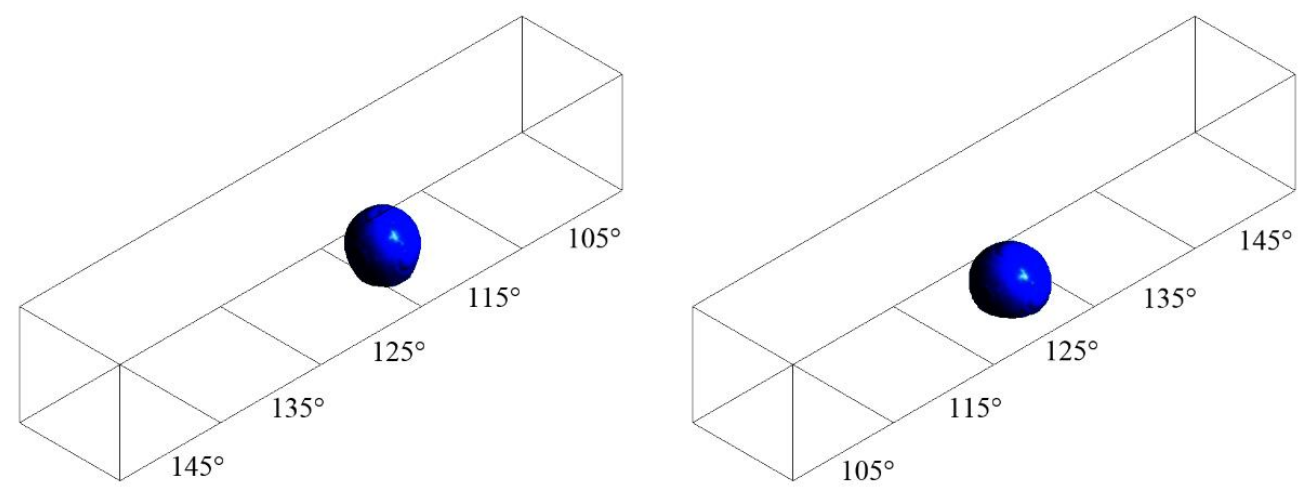

(b) $t=4 \mathrm{~ms}$

Figure 8. Cont. 

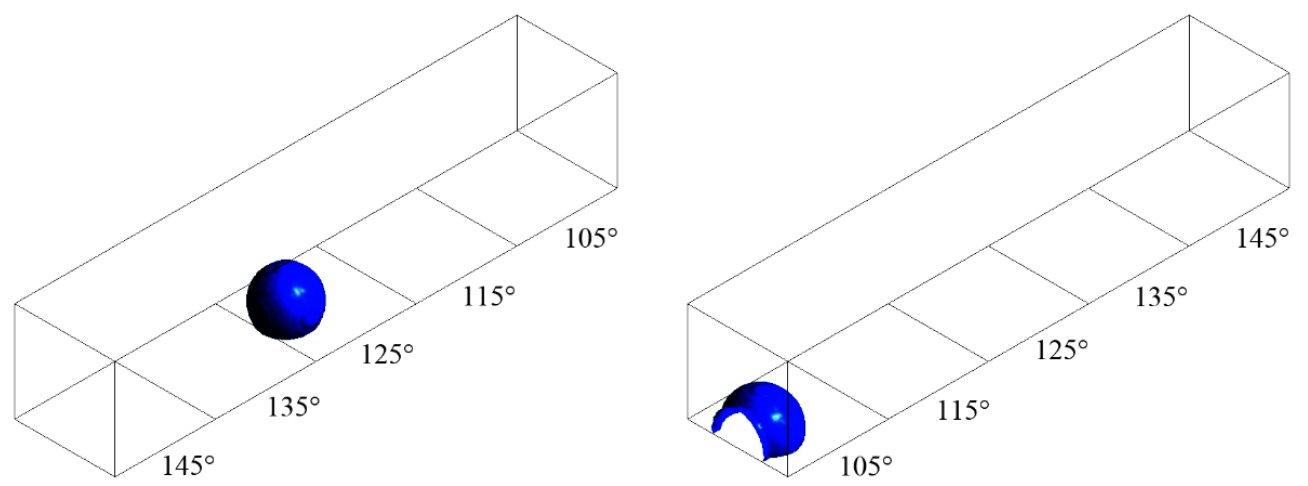

(c) $t=10 \mathrm{~ms}$

Figure 8. Water droplet behavior in the channel with varied wettability at different moments.

Although the average contact angles of the two forms of channels were the same, the droplets couldn't move to the outlet in the increasing flow channel to realize "self-draining". The results indicate that decreasing the contact angle flow channel is beneficial for water drainage in the fuel cells.

In order to verify that the modified GDL surface is available for water drainage, the conventional GDLs with constant static contact angles, $105^{\circ}$ and $145^{\circ}$, were also studied in the following research for comparison. The water droplet dynamics in the flow channel with varied wettability compared with the conventional flow channel with an initial droplet velocity of $0.5 \mathrm{~m} \cdot \mathrm{s}^{-1}$ is shown in Figure 9. The left three figures correspond to the time instant of $2 \mathrm{~ms}$, while the right three are at $10 \mathrm{~ms}$. In the first few milliseconds, the location of the droplet was nearest to the entrance of the traditional surface with a contact angle of $105^{\circ}$, which indicated that the smaller the hydrophobic angle was, the slower the droplets moved.

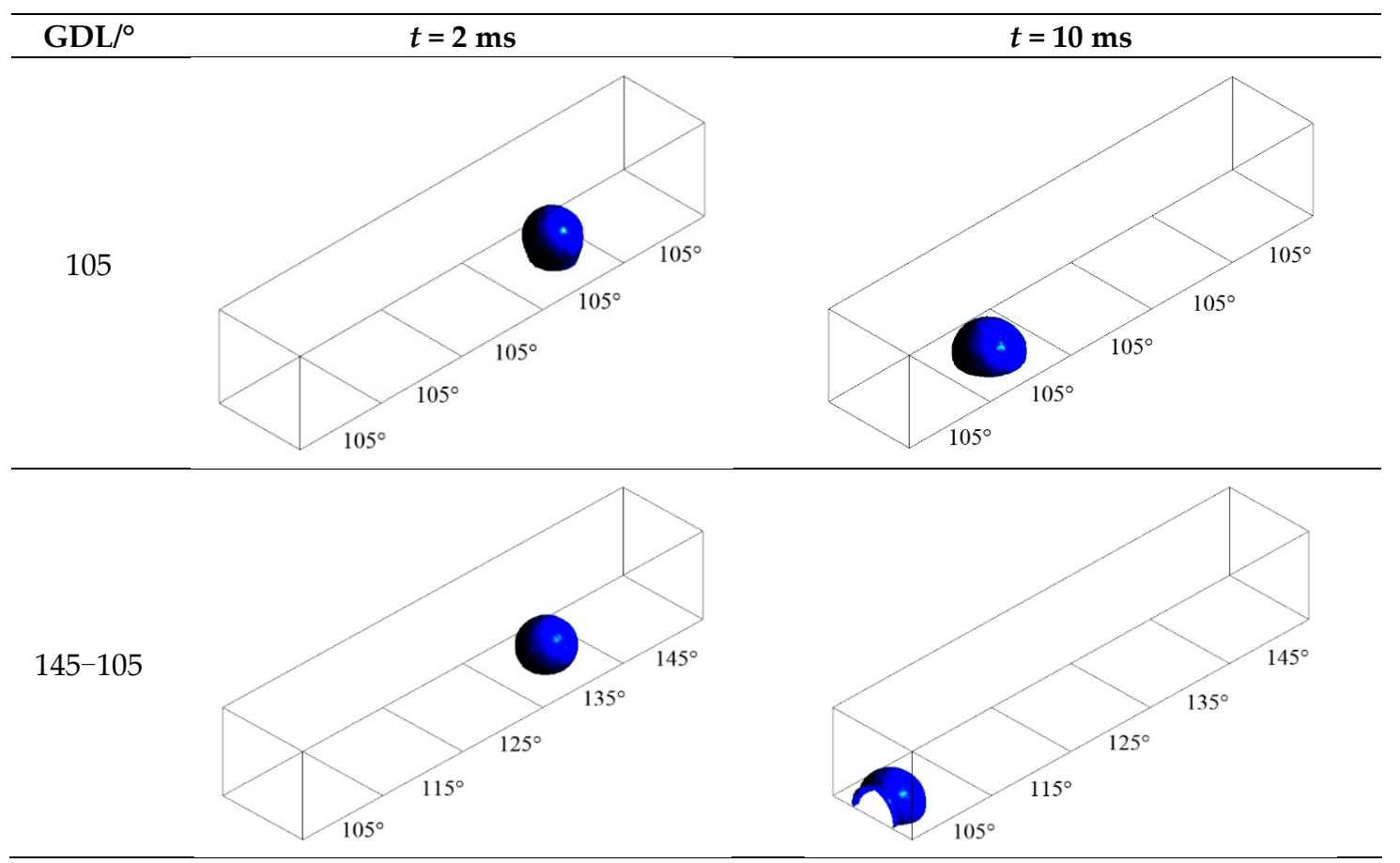

Figure 9. Cont. 


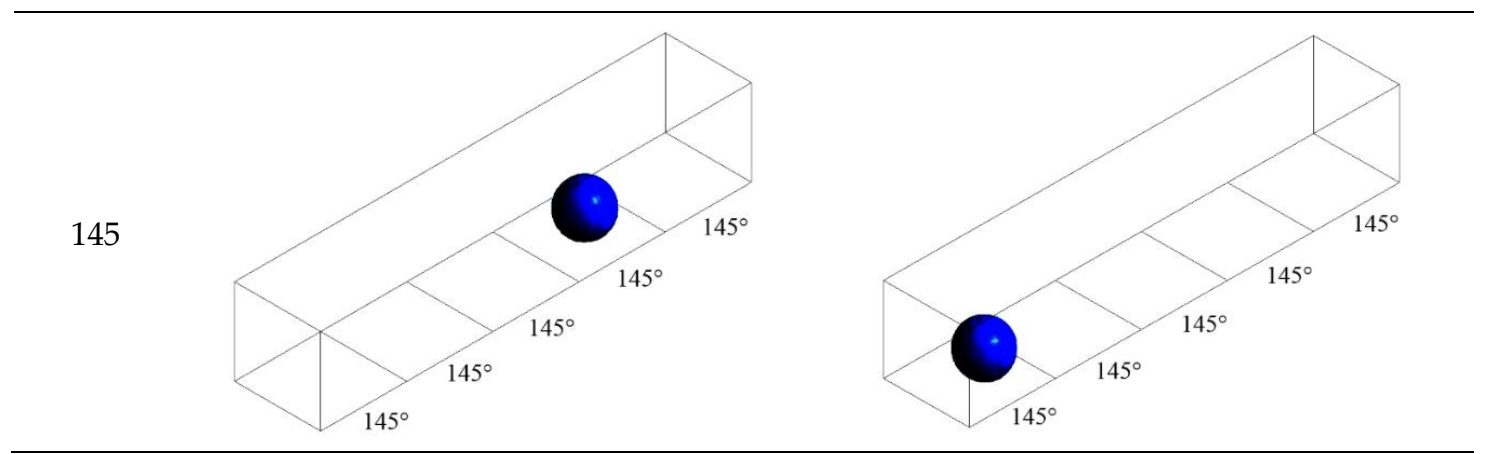

Figure 9. Water droplet dynamics in the flow channel with varied wettability compared with the conventional flow channel (velocity is $0.5 \mathrm{~m} \cdot \mathrm{s}^{-1}$ ).

The moving distances were almost the same in the channels with traditional surfaces with a contact angle of $145^{\circ}$ and the modified GDL surface. Once the droplets moved across the first part, the advantage of modified GDL surface gradually appeared. The decrease of the wettability could lead to an increased area of infiltration and a more serious deformation in the forward direction, and would generate potential energy for rolling forward. Combined with the velocity contours in the channel given in Figures 10 and 11, which shed the velocity distributions of the interface $x=0$ at the time instant of $1 \mathrm{~ms}$, while the water droplets pass the first interface of wettability discontinuity in the channel with varied contact angle. The mixture velocity around the droplet was higher with varied wettability than that of constant contact angle of $145^{\circ}$, due to the decrease of contact angle accelerating the amount of water moving to and infiltrating the bottom. It was clearly seen that the water droplets moved the fastest with the modified surface design than the two conventional designs at $10 \mathrm{~ms}$, though the constant contact angle of $145^{\circ}$ was bigger than the average contact angle of the modified surface.

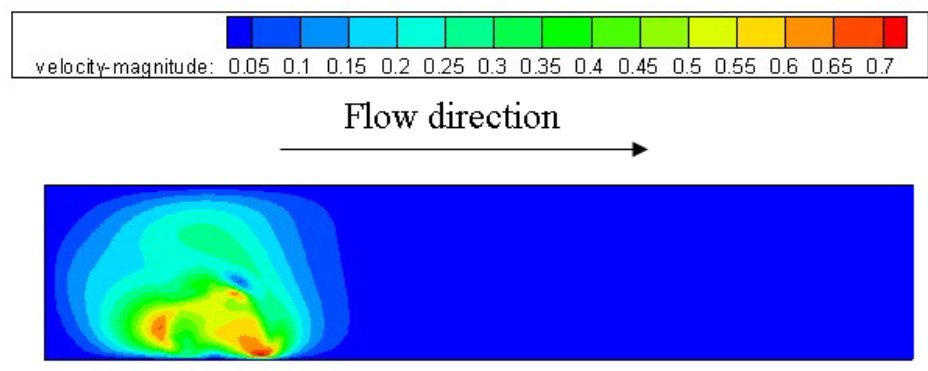

Figure 10. Velocity contour in the channel with varied contact angle from $145^{\circ}$ to $105^{\circ}(t=1 \mathrm{~ms})$.

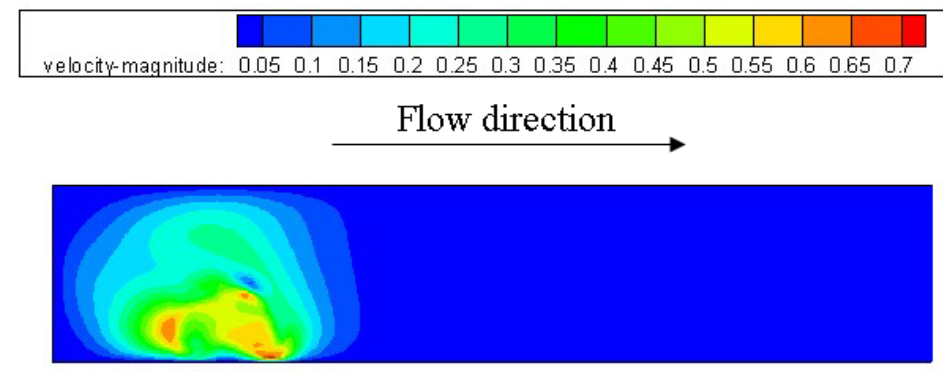

Figure 11. Velocity contour in the channel with constant contact angle of $145^{\circ}(t=1 \mathrm{~ms})$.

The water droplet dynamics in the flow channel with a gradually decreasing surface contact angle from $145^{\circ}$ to $105^{\circ}$, initial velocity of $0.5 \mathrm{~m} \cdot \mathrm{s}^{-1}$, and initial radius of $0.25 \mathrm{~mm}$ are shown in Figure 12. 
The movement process took $10 \mathrm{~ms}$ from inlet to outlet, and the shape of water droplets changed while rolling in the channel. The water droplet was close to spherical in shape at the beginning, and gradually spread on the hydrophobic surface in the flow channel in a hemispherical shape at the exit. In addition, the distance of the droplet movement in $1 \mathrm{~ms}$ was gradually reduced, which was due to the consumption of kinetic energy to overcome the wall adhesion. Figure 13 shows the advancing and receding contact angles of the water droplet in the first $3 \mathrm{~ms}$. Both contact angles decreased with the moving process, and the more severe the advancing contact angles were. The contact angle hysteresis was decreasing, leading to a slowing down of the velocity. Though the forward and receding angles of the droplets were almost equal at $3 \mathrm{~ms}$, the droplets would continue to flow to the outlet as the droplets still have a velocity.

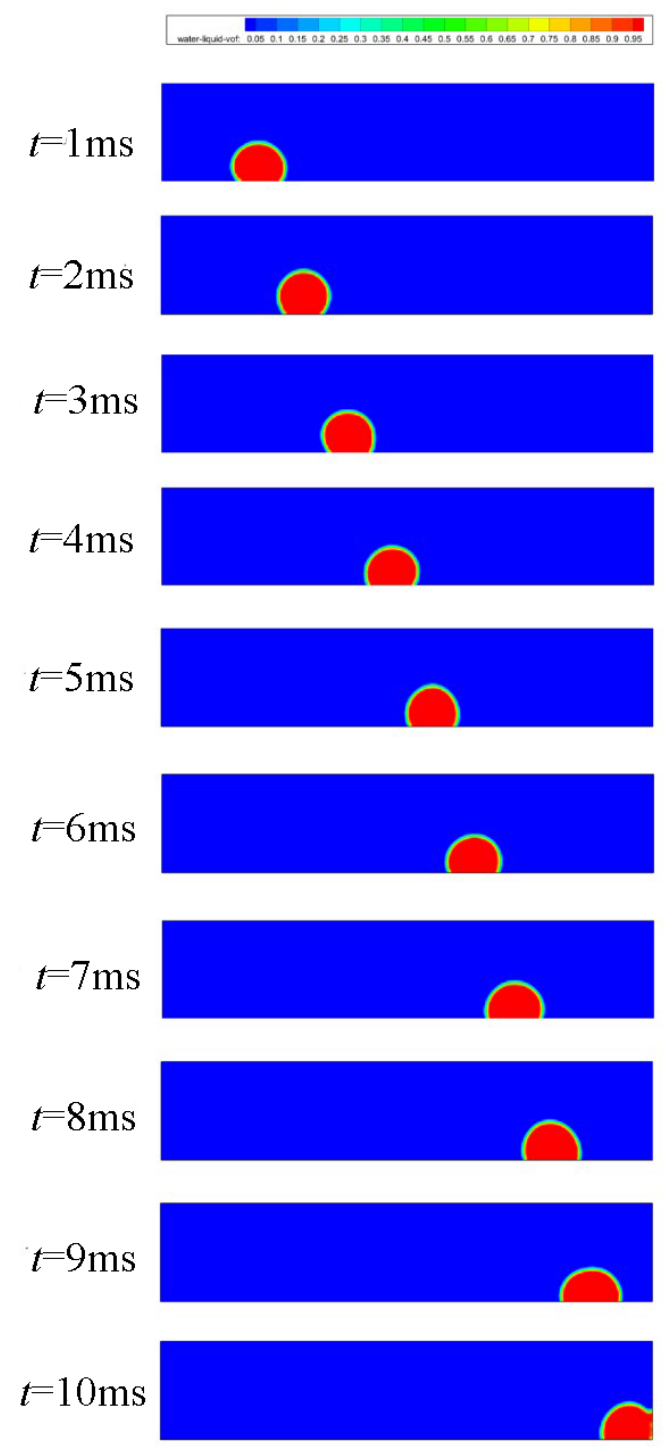

Figure 12. Water droplet dynamics in the flow channel with modified GDL surface. 


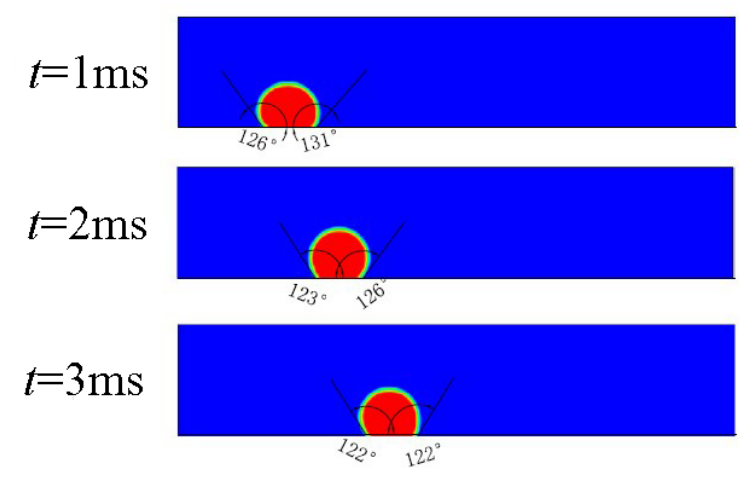

Figure 13. Advancing and receding contact angles during water droplet moving in the flow channel.

Comparing the modified flow channel and a conventional flow channel, the times consumed for the water droplets to reach and leave the division surfaces are shown in Figure 14. Before reaching the first interface, the modified flow channel was equivalent to a conventional flow channel with $\mathrm{s}$ contact angle of $145^{\circ}$, so the times required to reach the first interface $1 \mathrm{~mm}$ from the entrance were the same in the two cases. Moreover, the case with contact angle of $105^{\circ}$ almost coincided with the two cases, due to fact the initial velocity plas a more important role in the initial phase of the movement. With the movement of the water droplet, the differences between the three cases became evident. Taking a point $4 \mathrm{~mm}$ from the entrance as an example, the time used for reaching the fourth interface were $7.29 \mathrm{~ms}, 8.07 \mathrm{~ms}$, and $1.095 \mathrm{~ms}$, while the leaving times were $8.79 \mathrm{~ms}, 9.77 \mathrm{~ms}$ and $1.484 \mathrm{~ms}$, respectively. It was observed that water droplets moved the fastest with the modified surface design than the two conventional designs, and the conventional design with bigger contact angle showed better drainage properties. Furthermore, the movement of water droplets gradually slowed down as kinetic energy was consumed for the same structure, while times needed for crossing the interfaces were increasing. Taking the modified surface design for example, the time spent on passing the interfaces from the inlet to the outlet was $1.13 \mathrm{~ms}, 1.26 \mathrm{~ms}, 1.32 \mathrm{~ms}$ and $1.50 \mathrm{~ms}$, respectively.

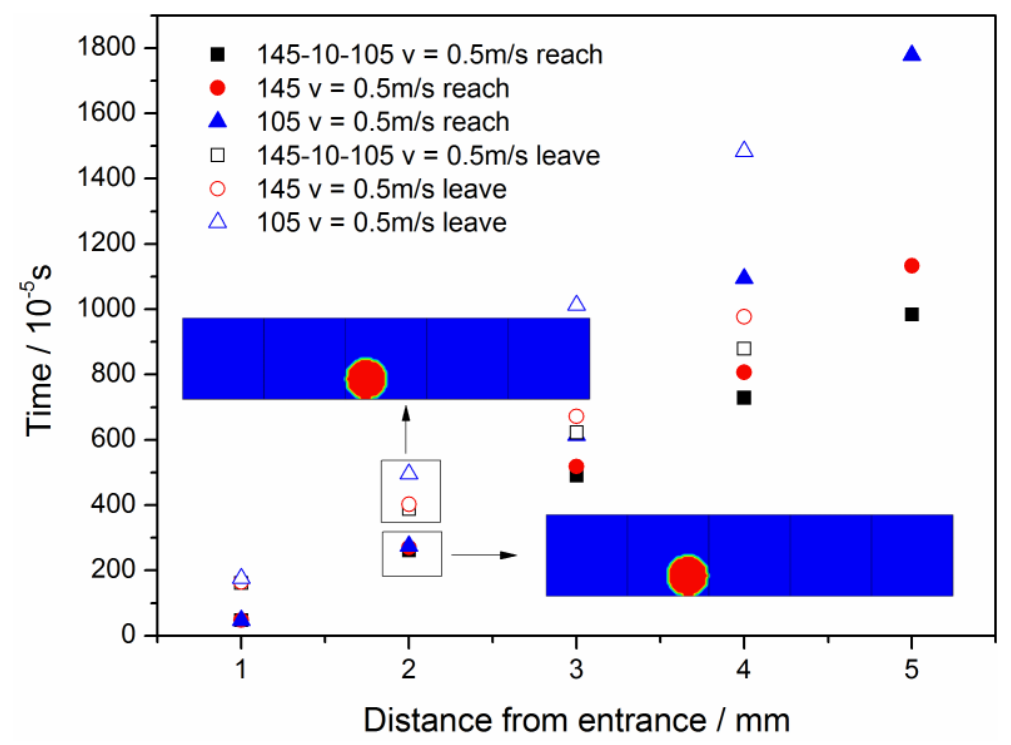

Figure 14. Comparison of time consumed between the modified flow channel and a conventional flow channel.

The time consumed for a water droplet to reach and leave the division surfaces with different initial velocities is shown in Figure 15. Obviously, it took less time to arrive at the same position with 
higher initial velocity. Water droplets with a velocity of $1.5 \mathrm{~m} \cdot \mathrm{s}^{-1}$ reached the outlet first using less than $3 \mathrm{~ms}$, while nearly $10 \mathrm{~ms}$ were needed with a velocity of $0.5 \mathrm{~m} \cdot \mathrm{s}^{-1}$. Moreover, the higher the initial velocity was, less time would be spent across the interface between two parts with different surface wettability.

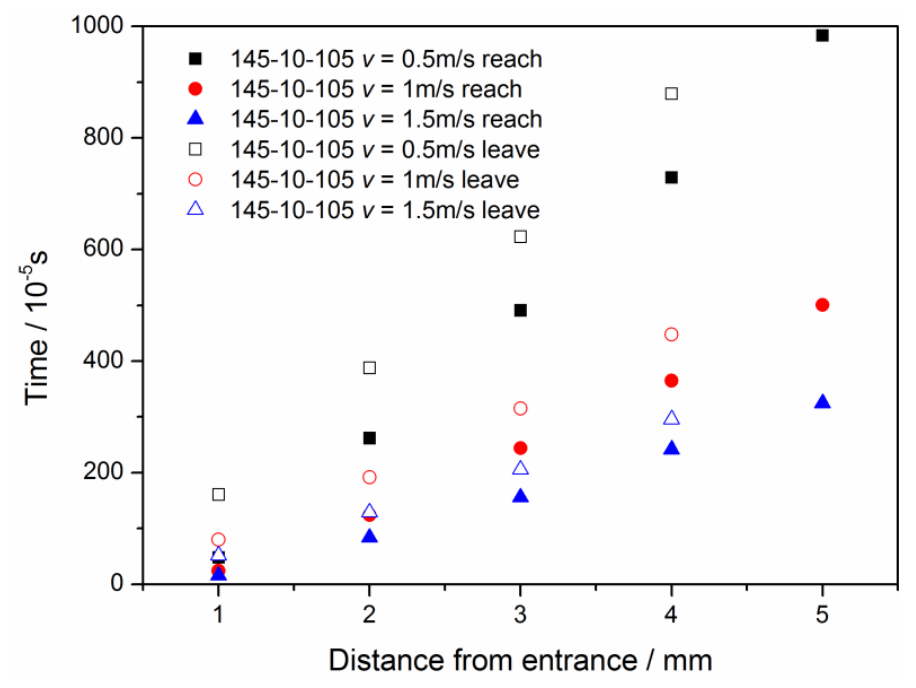

Figure 15. Comparison of times consumed with different initial velocities.

A comparison of different modified surface designs with same the initial velocity is shown in Figure 16. The fixed variation of surface static contact angle was respectively set to $5^{\circ}, 10^{\circ}$, and $15^{\circ}$ from the inlet to outlet. It was clear that the modified surface with $15^{\circ}$ variation showed the best drainage properties, due to the fact it resulted in the shortest time for water droplets to be removed out of the flow channel. This seems contradictory with what was previously mentioned, that bigger contact angles showed better drainage properties, a bigger variation indicating a smaller average contact angle. This was because the bigger variation leads to a more severe deformation of the water droplets, and more surface energy would be transformed into kinetic energy. The times for water droplets to reach the exit were respectively $1.069 \mathrm{~ms}, 9.84 \mathrm{~ms}$ and $8.84 \mathrm{~ms}$ with the increasing contact angle variation.

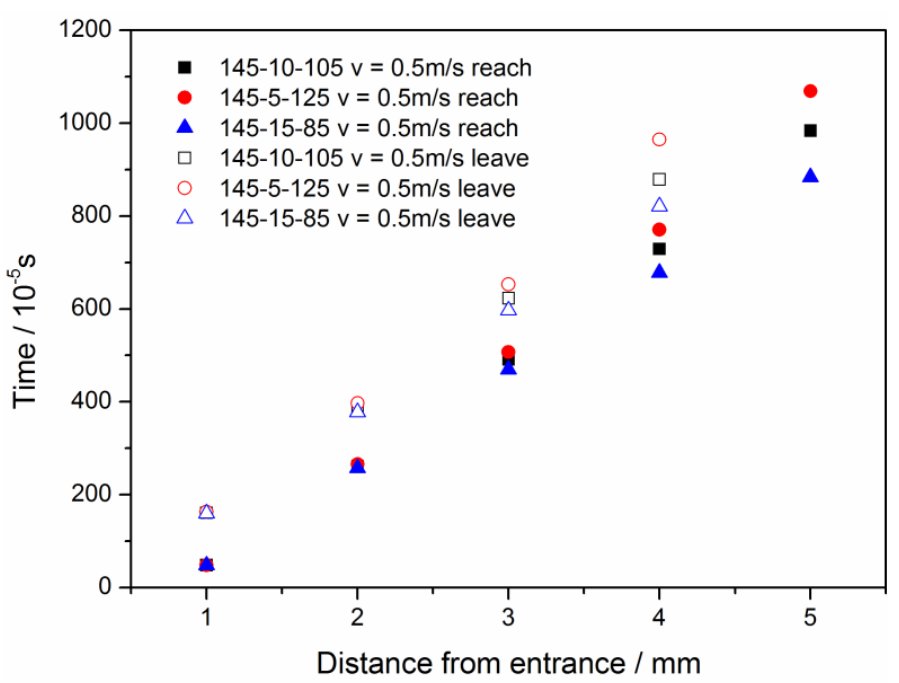

Figure 16. Comparison of times consumed with different modified GDL surfaces. 
The effect of different initial water droplet radius is shown in Figure 17. The case of $0.3 \mathrm{~mm}$ radius showed the best performance, though the case of $0.2 \mathrm{~mm}$ left the first part of the flow channel firstly. At the beginning of the movement, the water droplets of different radius were almost the same, and the $0.2 \mathrm{~mm}$ radius, with a smaller forward resistance due to its smaller windward area moved faster than droplets with other radii. When the water droplets rolled in the channel, those with a larger radius with more severe deformation gradually moved faster than the other two radii. The water droplet of $0.3 \mathrm{~mm}$ radius took $9.43 \mathrm{~ms}$ to reach the exit, while the $0.25 \mathrm{~mm}$ and $0.2 \mathrm{~mm}$ radius droplets took $9.84 \mathrm{~ms}$ and $10.66 \mathrm{~ms}$, respectively.

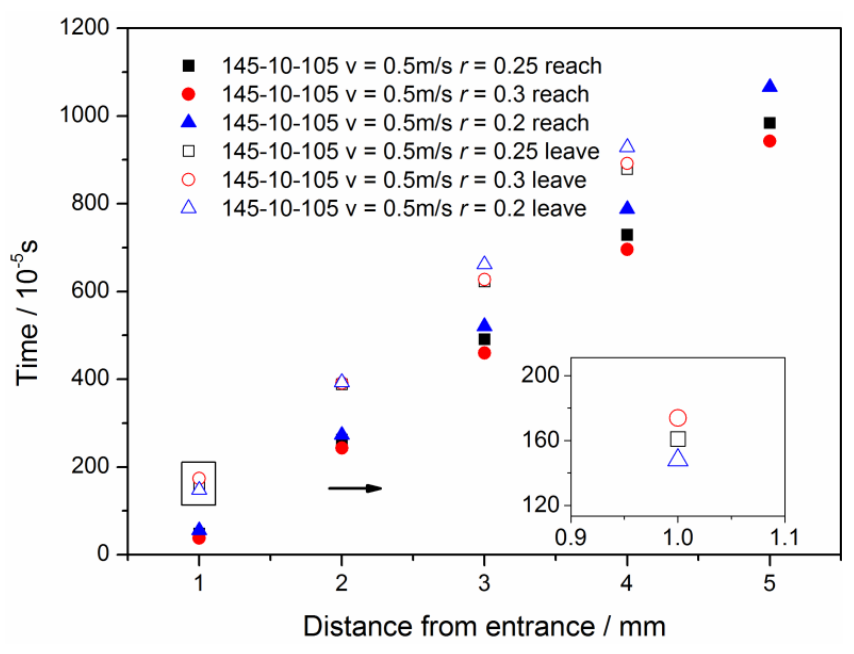

Figure 17. Comparison of time consumed with different initial radius of the water droplet.

\subsection{Straight Channel Configuration with a Water Inlet Hole}

\subsubsection{Without Considering Phase Transition}

Figure 18 shows the time evolution of the water droplets emerging from the hole in a hydrophobic GDL surface with a static contact angle of $135^{\circ}$. In the first few milliseconds, water gradually gathered around the GDL hole and formed a droplet attach to the GDL surface $(t=3 \mathrm{~ms})$. As the droplet grew, it began to move away from the edges of the hole, and then the shaped water droplet rolled along the GDL surface under the shear stress of air flow while water continually gathered around the GDL hole. At the time instant of $12 \mathrm{~ms}$, there were three droplets inside the flow channel, two shaped and one growing. Then, as time went on, the droplet closer to the outlet was blown out of the channel $(t=15 \mathrm{~ms})$. Moreover, the movements of water droplets were along the middle of the channel without contacting the side walls. That way, the dynamics of water droplets for hydrophobic GDL surfaces was not affected by the wettability of channel side walls, whether they were hydrophilic or hydrophobic.

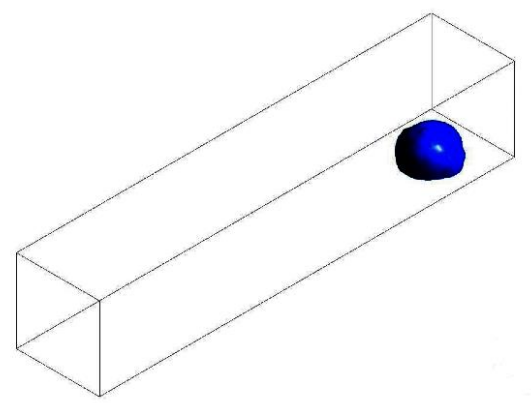

(a) $t=3 \mathrm{~ms}$

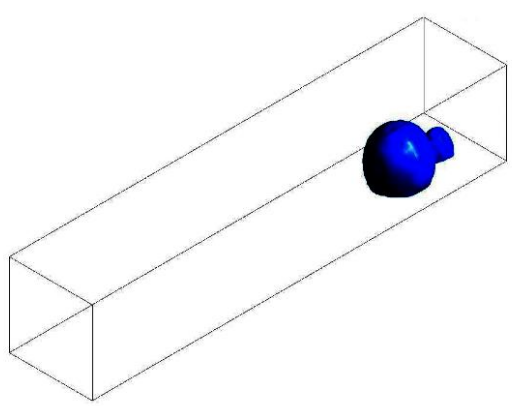

(b) $t=6 \mathrm{~ms}$

Figure 18. Cont. 


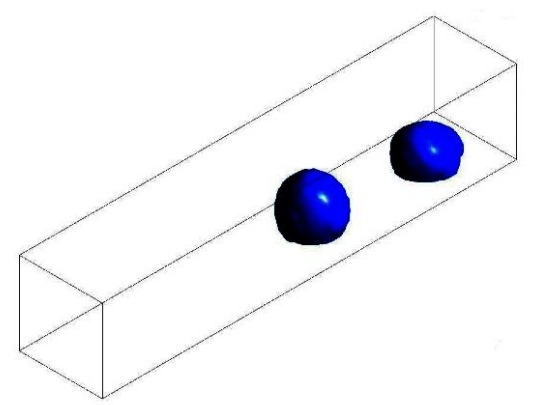

(c) $t=9 \mathrm{~ms}$

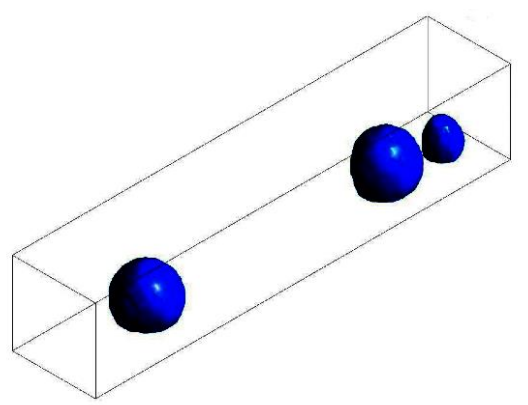

(d) $t=12 \mathrm{~ms}$

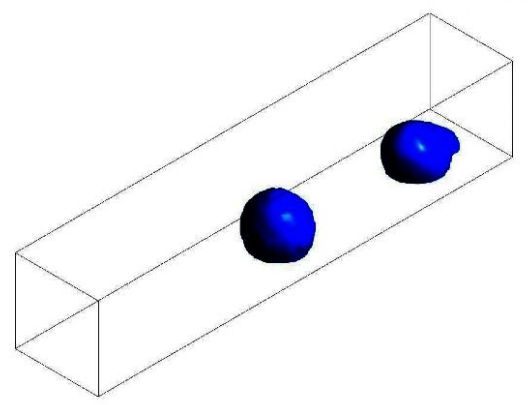

(e) $t=15 \mathrm{~ms}$

Figure 18. Time evolution of the water droplets emerging from the hole in a hydrophobic GDL surface (the GDL surface contact angle is $135^{\circ}$ ).

Different properties of side walls presented different evolution progress of the water droplet emergence from the hole in a hydrophilic GDL surface, shown in Figure 19. For a hydrophilic GDL surface, water spilt from the GDL hole, and spread downstream towards both side walls of the channel in the form of water film. When the side walls were hydrophilic, the water film attached to them and tore into two parts, gathering in the interfaces of side walls and the surface of the GDL. As time went on, the water gathering around the interfaces would not be easily blown away.

Before the water film reached the side walls, the characteristics of water transport were the same, regardless of the wettability of side walls. The water film would keep spreading downstream along the GDL surface while it attached to hydrophobic side walls. The GDL surface with large coverage by a water film would severely hinder the reactants' transfer from flow channels to the GDLs, which severely affected the performance of the fuel cell. Compared with Figure 18, hydrophobic surface of channel walls would accelerate the removal of water.

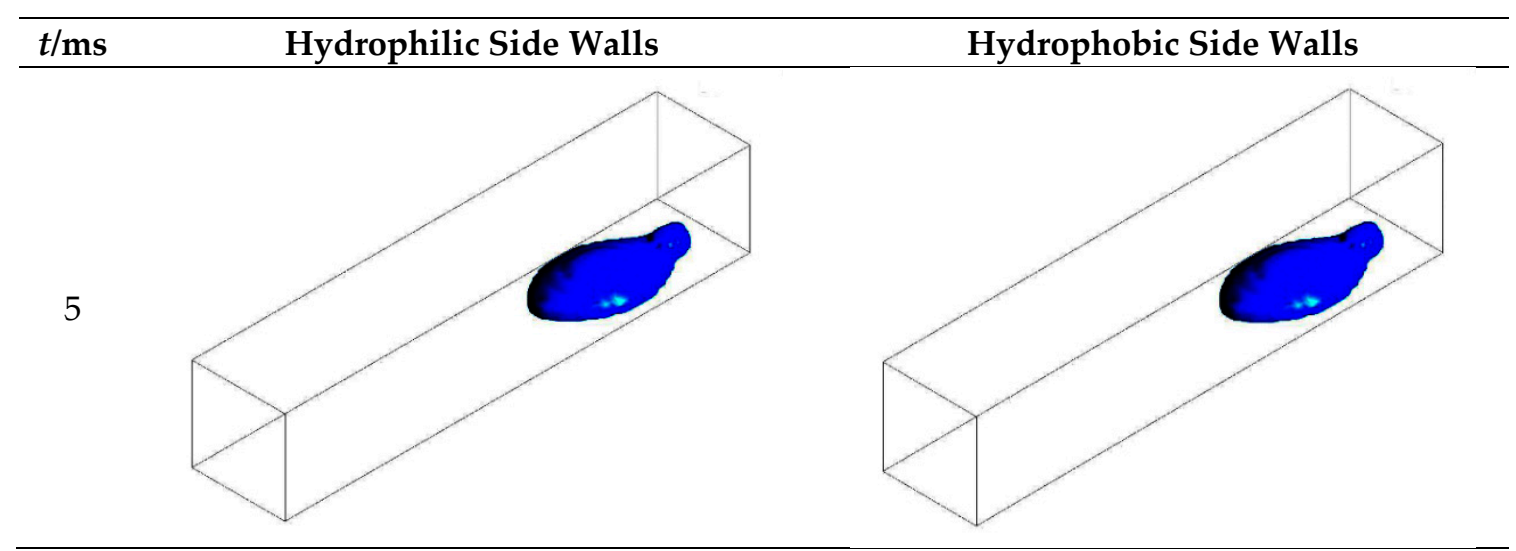

Figure 19. Cont. 


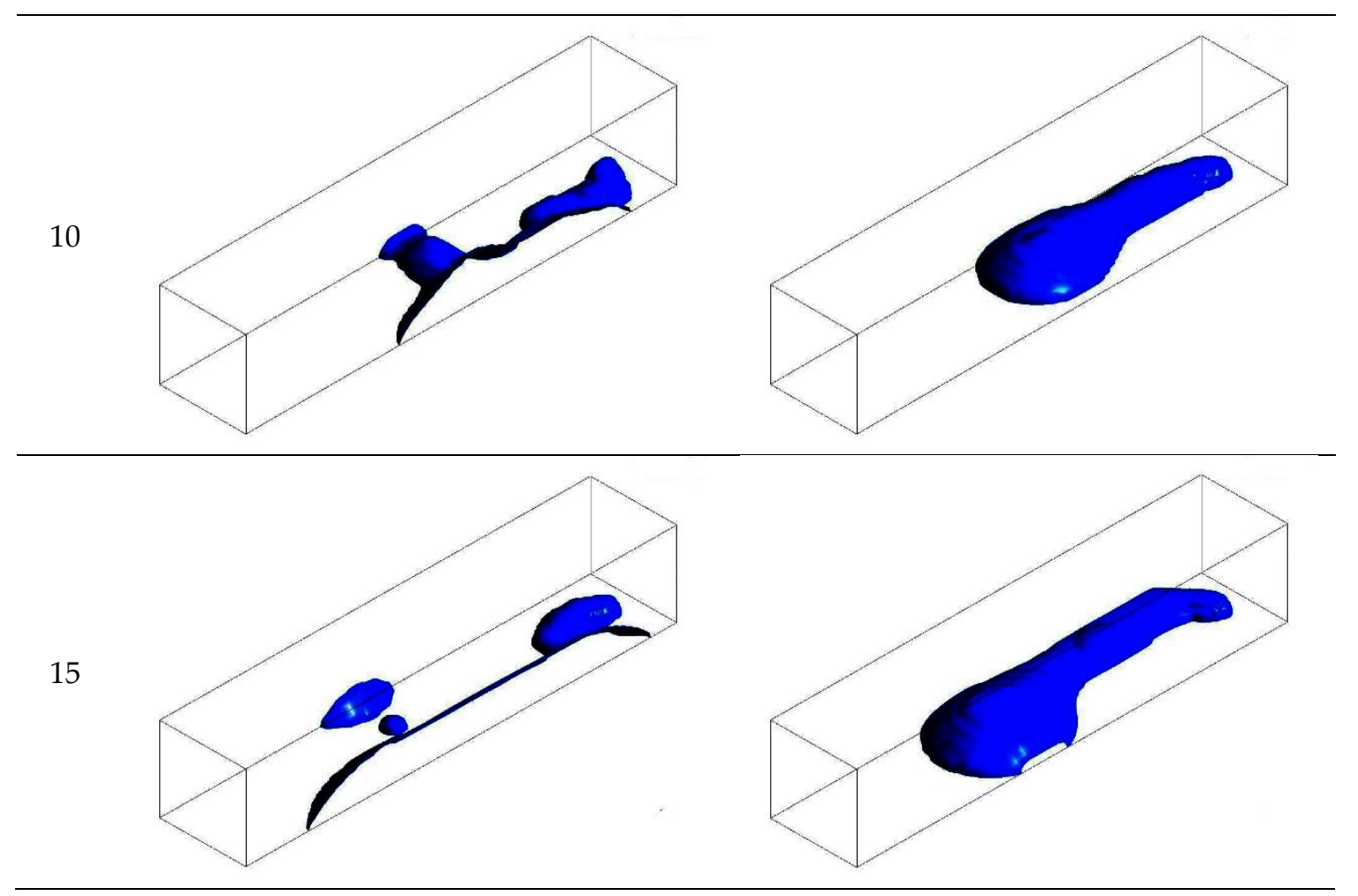

Figure 19. Time evolution of the water droplet emerging from the hole in hydrophilic GDL surface (The GDL surface contact angle is $45^{\circ}$ ).

The pressure difference between air inlet and outlet with different surface properties is shown in Figure 20. Due to the similar water droplet dynamics for the hydrophobic surface of the gas diffusion layer, with hydrophilic side walls or hydrophobic side walls, there are only three curves in Figure 18.

For a hydrophobic GDL surface, the pressure drop tended to be on the rise before $13 \mathrm{~ms}$, and then the pressure level dropped sharply followed by a continuous rise. The sharp pressure drop was caused by the blowing away of the water droplets, and the continuous rise corresponds to the emergence of the new droplets.

For a hydrophilic GDL surface, the time evolution of the pressure drop kept increasing with hydrophobic side walls. Hydrophobic side walls forced the water film to spread along the GDL surface, and the area covered by the water film increased with the increasing number of iterations. Within the first $5 \mathrm{~ms}$ to $6 \mathrm{~ms}$, the curve of hydrophilic side walls was coincident with the curve of hydrophobic side walls. However, the curve of hydrophilic sidewalls showed a fluctuation at $8 \mathrm{~ms}$. The pressure drop was due to the appearance of adsorption of water by the side walls, while the rise was due to the water accumulation along the interface between the GDL surface and side walls. 


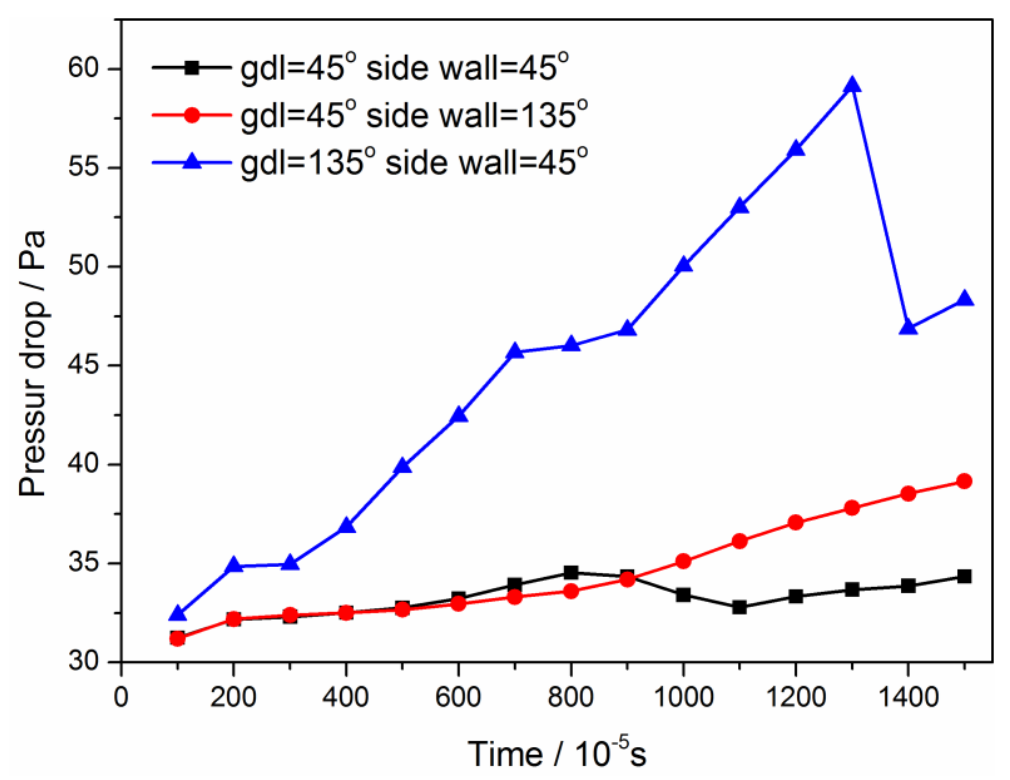

Figure 20. Pressure drop.

In a word, the pressure drop characteristics were consistent with the droplet movement characteristics. Though a hydrophobic GDL surface was beneficial for water removal, the pressure drop was much larger than that of a hydrophilic gas diffusion layer surface. The energy consumption due to pressure change was not so obvious in the whole fuel cell system, so a hydrophobic GDL with contact angle about $130^{\circ}$ was used in practical applications.

\subsubsection{Considering Phase Transition}

Phase transition during the operation of PEM fuel cell should be considered, which would have important effects on water transport, due to the coexistence of liquid water and water vapor in the flow channel. The source terms of mass and energy had been added by UDFs, which contain five parameters: saturation vapor pressure, actual water vapor partial pressure, source term of liquid water, source term of water vapor and the latent heat due to phase transition. Saturation vapor pressure could be calculated using the parameters of temperature, actual water vapor partial pressure which is related to the mass fraction and the molecular weight of each species. The source term of liquid water and water vapor could be calculated according to Equation (7), and the latent heat due to phase transition could be obtained according to Equation (9). Based on configuration 3, the temperature boundary condition had been set to $353 \mathrm{~K}$, and the initial liquid water volume had been set to 0.1 in the phase transition condition. Similarly, hydrophilic and hydrophobic surfaces are discussed in the paper.

Compared with the cases without considering phase transition, the amount of liquid water in Figure 21 was less than that in Figures 18 and 19. The main reason was that the liquid water volume fraction was set to 0.1 in the phase transition model instead of 1 in the simple flow model. In addition to the quantitative change, the flow pattern of liquid water displayed a big difference. Whether a water droplet or a water film was considered, the behaviors were continuous, smooth, attached to or limited by GDL surface and side walls in the simple flow model. At the same time, water droplets and water films were irregular, scattered and rough, and even suspended in the flow channel when using the phase transition model. The irregular shape of water droplets was the result of the non-uniformity of the temperature distribution with the flow of air.

For hydrophilic or hydrophobic surfaces, liquid water gathered around the hole at the time instant of $1 \mathrm{~ms}$. With the continuous influent mixture of liquid water and water vapor, water droplets overcame the adsorption of the GDL hole and began to spread on the hydrophilic GDL surface, while new droplets would form around the initial droplet for hydrophobic surfaces. 

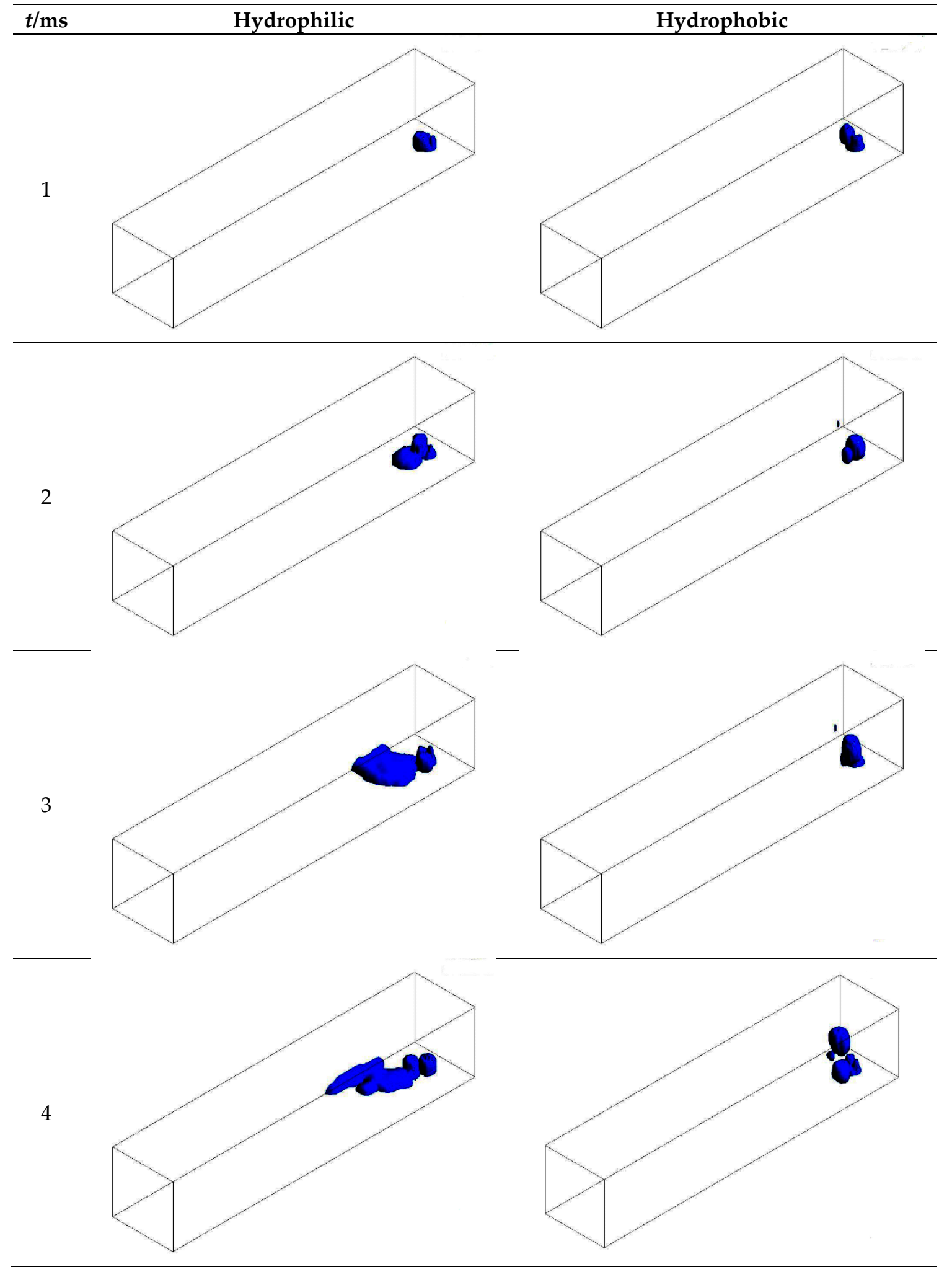

Figure 21. Cont. 


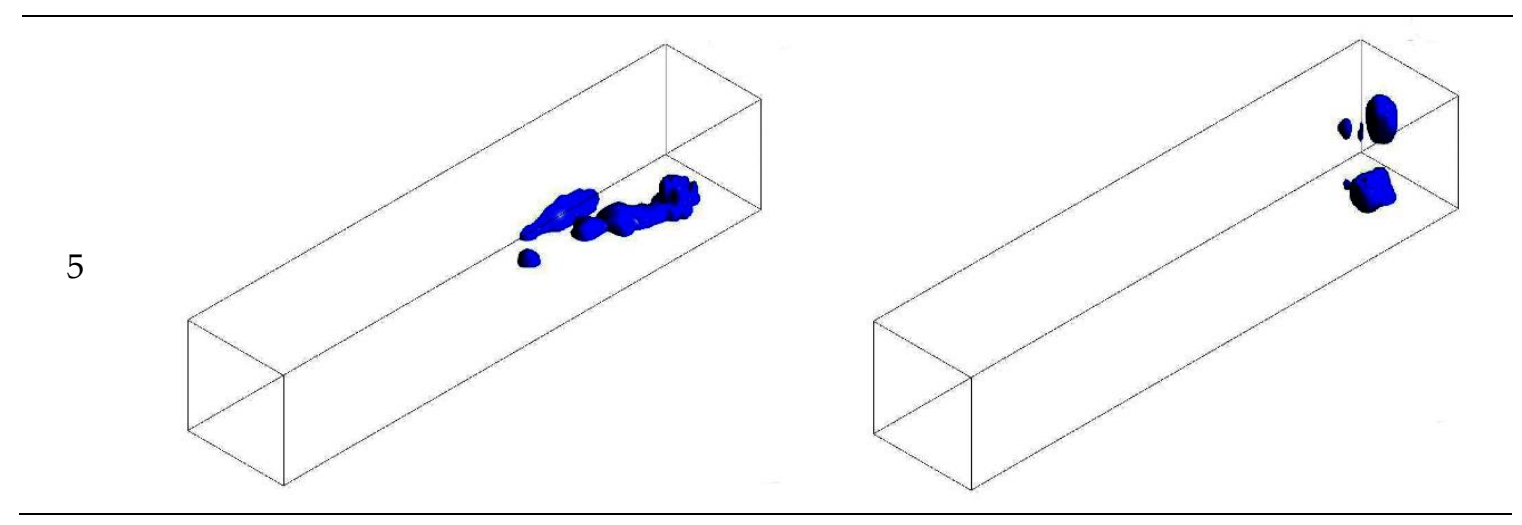

Figure 21. Time evolution of water transport (All the surfaces contact angles are $45^{\circ}$ and all the surfaces contact angles are $135^{\circ}$ ).

With time, the amount of liquid water gathered in the flow channel increased, leading to a larger area covered by water film and larger droplets above the GDL hole. At last, the water film spread to the side walls, was absorbed by the side walls, and flowed to the outlet. Water droplets grew, split into several small ones, and grew again, partly on the surfaces of the flow channel, and partly suspended in the flow channel.

It is clearly seen that hydrophilic condition was beneficial for water drainage, with a water film in the middle section of the flow channel at $5 \mathrm{~ms}$ while water droplets were just in the inlet of the flow channel for hydrophobic conditions. The water removal rate and the effective diffusion area should be balanced.

\section{Conclusions}

Three simplified configurations were proposed for numerical simulation of the water transport in a PEMFC flow channel, based on the VOF method. In an open system, a higher inlet flow velocity accelerated water drainage in the conventional straight channel. A hydrophobic surface was the preferable design for water removal. Unexpectedly, the droplets with larger radius were easier to remove from the flow channel. Due to the comparatively higher air shear force and surface tension, the larger radius droplets with more severe deformation moved faster in the later phases of the flow.

Besides, water droplet emergence from the water inlet hole without considering phase transition, led to the same conclusion. However, when considering phase transition, hydrophilic conditions were beneficial for water drainage with a faster removal rate. Droplets of different sizes would suspend in the flow channel for hydrophobic conditions, which would be suitable for reactant diffusion, but water might accumulate leading to flooding in the flow channel. The water removal rate and the effective diffusion area should be balanced in practical use.

In a closed system, water droplets could flow out of the flow channel without external force, just requiring an appropriate initial velocity with varied and decreasing surface contact angle of the hydrophobic surface. Compared with the conventional case of constant surface contact angle, the channel with varied wettability performed the best. The performance of the modified model was related to the initial state of droplets and surface optimization characteristics.

Visualization experiments to observe the motion characteristics of liquid water in the flow channel, and the influence of optimized channel shape $[34,35]$ on droplet behavior will be considered in our future studies. And we have studied the optimal structural design of heat transfer element [36-39] based on Multi-Objective Genetic Algorithm, which could be used in the optimization design of fuel cell to obtain the good water and thermal managements in our future investigation. 
Author Contributions: Investigation, F.L.; Resources, Z.L.; Data Curation, J.S.; Writing-Original Draft Preparation, J.S.; Writing-Review \& Editing, Z.L.; Visualization, Z.L.; Supervision, Z.L., W.L.

Funding: This work is financially supported by the National Natural Science Foundation of China (Nos. 51736004 and 51776079).

Conflicts of Interest: The authors declare no conflict of interest.

\section{Abbreviation}

$c_{p} \quad$ Specific heat capacity $\mathrm{kJ} \cdot \mathrm{kg}^{-1} \cdot \mathrm{K}^{-1}$

$c_{r} \quad$ Condensation rate constant $\mathrm{s}^{-1}$

$h_{L} \quad$ Latent heat of vaporization $\mathrm{kJ} \cdot \mathrm{kg}^{-1}$

i Species

$k$ Curvature

$k^{e f f}$ Effective thermal conductivity $\mathrm{W} \cdot \mathrm{m}^{-1} \cdot \mathrm{K}^{-1}$

$r_{w} \quad$ Condensation rate $\mathrm{kg} \cdot \mathrm{m}^{-3} \cdot \mathrm{s}^{-1}$

$t$ Time s

$u \quad$ Velocity $\mathrm{m} \cdot \mathrm{s}^{-1}$

$\alpha \quad$ Volume fraction

$\mu \quad$ Dynamic viscosity $\mathrm{N} \cdot \mathrm{s} \cdot \mathrm{m}^{-2}$

$\rho \quad$ Volume average density $\mathrm{kg} \cdot \mathrm{m}^{-3}$

$\sigma \quad$ Surface tension $\mathrm{N} \cdot \mathrm{m}^{-1}$

\section{References}

1. Wang, Y.; Chen, K.S.; Mishler, J.; Cho, S.C.; Adroher, X.C. A review of polymer electrolyte membrane fuel cells: Technology, applications, and needs on fundamental research. Appl. Energy 2011, 88, 981-1007. [CrossRef]

2. Chen, Y.H.; Chen, C.Y.; Lee, S.C. Technology forecasting of new clean energy: The example of hydrogen energy and fuel cell. Afr. J. Bus. Manag. 2010, 4, 1372-1380.

3. Stambouli, A.B. Fuel cells: The expectations for an environmental-friendly and sustainable source of energy. Renew. Sustain. Energy Rev. 2011, 15, 4507-4520. [CrossRef]

4. Castelain, C.; Lasbet, Y.; Auvity, B.; Peerhossaini, H. Experimental study of the thermal performance of chaotic geometries for their use in PEM fuel cells. Int. J. Therm. Sci. 2016, 101, 181-192. [CrossRef]

5. Jung, S.H.; Kim, S.L.; Min, S.K.; Park, Y.; Lim, T.W. Experimental study of gas humidification with injectors for automotive PEM fuel cell systems. J. Power Sources 2007, 170, 324-333. [CrossRef]

6. Chen, B.; Wang, J.; Yang, T.; Cai, Y.; Pan, M.; Tu, Z.; Zhang, C.; Chan, S.H.; Yu, Y. Mitigation studies of carbon corrosion by optimizing the opening size of the cathode outlet in a proton exchange membrane fuel cell with dead-ended anode. Energy Convers. Manag. 2016, 119, 60-66. [CrossRef]

7. Chen, B.; Wang, J.; Yang, T.; Cai, Y.; Zhang, C.; Chan, S.H.; Yu, Y.; Tu, Z. Carbon corrosion and performance degradation mechanism in a proton exchange membrane fuel cell with dead-ended anode and cathode. Energy 2016, 106, 54-62. [CrossRef]

8. Kandlikar, S.G.; See, E.J.; Gopalan, P.; Koz, M.; Banerjee, R. Two-phase Flow in GDL and Reactant Channels of a Proton Exchange Membrane Fuel Cell. Int. J. Hydrog. Energy 2014, 39, 6620-6636. [CrossRef]

9. Li, H.; Tang, Y.; Wang, Z.; Shi, Z.; Wu, S.; Song, D.; Zhang, J.; Fatih, K.; Zhang, J.; Wang, H.; et al. A review of water flooding issues in the proton exchange membrane fuel cell. J. Power Sources 2008, 178, 103-117. [CrossRef]

10. Misran, E.; Hassan, N.S.M.; Wan, R.W.D.; Majlan, E.H.; Rosli, M.I. Water transport characteristics of a PEM fuel cell at various operating pressures and temperatures. Int. J. Hydrog. Energy 2013, 38, 9401-9408. [CrossRef]

11. Lottin, O.; Antoine, B.; Colinart, T.; Didierjean, S.; Maranzana, G.; Moyne, C.; Ramousse, J. Modelling of the operation of Polymer Exchange Membrane Fuel Cells in the presence of electrodes flooding. Int. J. Therm. Sci. 2009, 48, 133-145. [CrossRef]

12. Wan, Z.; Liu, J.; Luo, Z.; Tu, Z.; Liu, Z.; Liu, W. Evaluation of self-water-removal in a dead-ended proton exchange membrane fuel cell. Appl. Energy 2013, 104, 751-757. [CrossRef] 
13. Wan, Z.; Wan, J.; Liu, J.; Tu, Z.; Pan, M.; Liu, Z.; Liu, W. Water recovery and air humidification by condensing the moisture in the outlet gas of a proton exchange membrane fuel cell stack. Appl. Therm. Eng. 2012, 42, 173-178. [CrossRef]

14. Liu, Z.; Shen, J.; Pei, H.; Tu, Z.; Wang, J.; Wan, Z.; Liu, W. Effect of humidified water vapor on heat balance management in a proton exchange membrane fuel cell stack. Int. J. Energy Res. 2015, 39, 504-515. [CrossRef]

15. Djilali, N.; Lu, D. Influence of heat transfer on gas and water transport in fuel cells. Int. J. Therm. Sci. 2002, 41, 29-40. [CrossRef]

16. Anderson, R.; Zhang, L.; Ding, Y.; Blanco, M.; Bi, X.; Wilkinson, D.P. A critical review of two-phase flow in gas flow channels of proton exchange membrane fuel cells. J. Power Sources 2010, 195, 4531-4553. [CrossRef]

17. Zhu, X.; Sui, P.; Djilali, N. Three-dimensional numerical simulations of water droplet dynamics in a PEMFC gas channel. J. Power Sources 2008, 181, 101-115. [CrossRef]

18. Jiao, K.; Zhou, B. Innovative gas diffusion layers and their water removal characteristics in PEM fuel cell cathode. J. Power Sources 2007, 169, 296-314. [CrossRef]

19. Amara, M.E.A.B.; Nasrallah, S.B. Numerical simulation of droplet dynamics in a proton exchange membrane (PEMFC) fuel cell micro-channel. Int. J. Hydrog. Energy 2015, 40, 1333-1342. [CrossRef]

20. Banerjee, R.; Kandlikar, S.G. Liquid water quantification in the cathode side gas channels of a proton exchange membrane fuel cell through two-phase flow visualization. J. Power Sources 2014, 247, 9-19. [CrossRef]

21. Gao, S.; Liao, Q.; Liu, W.; Liu, Z. Coalescence-Induced Jumping of Nanodroplets on Textured Surfaces. J. Phys. Chem. Lett. 2017, 9, 13-18. [CrossRef] [PubMed]

22. Gao, S.; Liao, Q.; Liu, W.; Liu, Z. Nanodroplets Impact on Rough Surfaces: A Simulation and Theoretical Study. Langmuir 2018, 34, 5910-5917. [CrossRef] [PubMed]

23. Ous, T.; Arcoumanis, C. Visualisation of water droplets during the operation of PEM fuel cells. J. Power Sources 2007, 173, 137-148. [CrossRef]

24. Lee, D.; Bae, J. Visualization of flooding in a single cell and stacks by using a newly-designed transparent PEMFC. Int. J. Hydrog. Energy. 2012, 37, 422-435. [CrossRef]

25. Zhan, Z.; Wang, C.; Fu, W.; Pan, M. Visualization of water transport in a transparent PEMFC. Int. J. Hydrog. Energy 2012, 37, 1094-1105. [CrossRef]

26. Kumbur, E.C.; Sharp, K.V.; Mench, M.M. Liquid droplet behavior and instability in a polymer electrolyte fuel cell flow channel. J. Power Sources 2006, 161, 333-345. [CrossRef]

27. Bazylak, A.; Sinton, D.; Liu, Z.S.; Djilali, N. Effect of compression on liquid water transport and microstructure of PEMFC gas diffusion layers. J. Power Sources 2007, 163, 784-792. [CrossRef]

28. Sinha, P.K.; Wang, C.Y. Pore-network modeling of liquid water transport in gas diffusion layer of a polymer electrolyte fuel cell. Electrochim. Acta 2007, 52, 7936-7945. [CrossRef]

29. Pasaogullari, U.; Wang, C.Y. Two-phase transport and the role of micro-porous layer in polymer electrolyte fuel cells. Electrochim. Acta 2004, 49, 4359-4369. [CrossRef]

30. Nam, J.H.; Kaviany, M. Effective diffusivity and water-saturation distribution in single-and two-layer PEMFC diffusion medium. Int. J. Heat Mass Transf. 2003, 46, 4595-4611. [CrossRef]

31. ANSYS 14.0 Help Connecting Modeling Multiphase Flows; ANSYS, Inc.: Canonsburg, PA, USA, 2011.

32. Han, B.; Meng, H. Lattice Boltzmann simulation of liquid water transport in turning regions of serpentine gas channels in proton exchange membrane fuel cells. J. Power Sources 2012, 217, 268-279. [CrossRef]

33. Han, B.; Yu, J.; Meng, H. Lattice Boltzmann simulations of liquid droplets development and interaction in a gas channel of a proton exchange membrane fuel cell. J. Power Sources 2012, 202, 175-183. [CrossRef]

34. Liu, Z.; Zeng, X.; Ge, Y.; Shen, J.; Liu, W. Multi-objective optimization of operating conditions and channel structure for a proton exchange membrane fuel cell. Int. J. Heat Mass Transf. 2017, 111, 289-298. [CrossRef]

35. Zeng, X.; Ge, Y.; Shen, J.; Zeng, L.; Liu, Z.; Liu, W. The optimization of channels for a proton exchange membrane fuel cell applying genetic algorithm. Int. J. Heat Mass Transf. 2017, 105, 81-89. [CrossRef]

36. Ge, Y.; Liu, Z.C.; Sun, H.N.; Liu, W. Optimal design of a segmented thermoelectric generator based on three-dimensional numerical simulation and multi-objective genetic algorithm. Energy 2018, 147, 1060-1069. [CrossRef]

37. Ge, Y.; Shan, F.; Liu, Z.C.; Liu, W. Optimal Structural Design of a Heat Sink with Laminar Single-Phase Flow Using Computational Fluid Dynamics-Based Multi-Objective Genetic Algorithm. J. Heat Transf. 2017, 140, 022803. [CrossRef] 
38. Ge, Y.; Liu, Z.C.; Liu, W. Multi-objective genetic optimization of the heat transfer for tube inserted with porous media. Int. J. Heat Mass Transf. 2016, 101, 981-987. [CrossRef]

39. Ge, Y.; Liu, Z.; Liu, W.; Chen, G. Active optimization design theory and method for heat transfer unit and its application on shape design of cylinder in convective heat transfer. Int. J. Heat Mass Transf. 2015, 90, 702-709. [CrossRef] 